DE-AC22-91PC91042-TPR-5

\title{
Effects of Low-Temperature Catalytic Pretreatments on Coal Structure and Reactivity in Liquefaction
}

\author{
Technical Prugress Report \\ December 1992 - March 1993
}

C. Song, A.K. Saini, K. Wenzel, L. Huang, P.G. Hatcher and H.H. Schobert

Fuel Science Program

Department of Materials Science and Engineering

The Pennsylvania State University

209 Academic Projects Building, University Park, Pennsylvania, PA 16802

April 1993

Prepared for the U.S. Department of Energy

under Contract No.

DE-AC22-91PC91042

DISCLAIMER

This report was prepared as an account of work sponsored by an agency of the United States This report was prepared as an account of work sponsored bovernent agency thereof, nor any of their employees, makes any warranty, express or implied, or assumes any legal liability or responsibility for the accuracy, completeness, or usefulness of any information, apparatus, product, or process disclosed, or represents that its use would not infringe privately owned rights. Reference herein to any specific commercial product, process, or service by trade name, trademark, manufacturer, or otherwise does not necessarily constitute or imply its endorsement, recommendation, or favoring by the United States Government or any agency thereof. The views and opinions of authors expressed herein do not necessarily state or reflect those of the United States Government or any agency thereof. 


\section{DISCLAIMER}

This report was prepared as an account of work sponsored by the United States Government. Neither the United States Government nor any agency thereof, nor any of their employees, makes any warranty express or implied, or assumes any legal liability or responsibility for the accuracy, completeness, or usefulness of any information, apparatus, product, or process disclosed, or represents that its use would not infringe privately owned rights. Reference herein to any specific commercial product, process or service by trade name, mark manufacturer, or otherwise, does not necessarily constitute or imply its endorsement, recommendation, or favoring by the United States Government or any agency thereof. The views and opinions of authors expressed herein do not necessarily state or reflect those of the United States Government or any agency thereof.

\section{ACKNOWLEDGEMENTS}

This on-going project is supported by the U.S. Department of Energy, Pittsburgh Energy Technology Center, in Advanced Coal Research Program. Currently Dr. M.A. Nowak is DOE/PETC Project Manager; Dr. M. J. Baird was the project manager during the first three quarterly periods. Drs. H.H. Schobert, C. Song and P.G. Hatcher are the Co-Principal Investigators at Penn State. The authors wish to express their appreciation to Drs. M.A. Nowak, M. J. Baird, S. Lee, and E. B. Klunder of DOE/PETC for their support of this effort. The authors would also like to thank Dr. A. Davis and Mr. D. Glick for providing coal samples and data from DOE/Penn State Coal Sample Bank, and Mr. R.M. Copenhaver for the fabrication of tubing bomb reactors. 


\section{TABLE OF CONTENTS}

\section{EXECUTIVE SUMMARY}

PROJECT OBJECTIVES

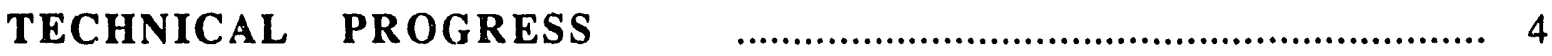

1. Influence of Drying and Oxidation of Coal on Coal Conversion and Products Distribution in Catalytic Liquefaction

2. Characterization of Dried and Oxidized Coal and the Insoluble Residues from Their Catalytic and Thermal Liquefaction

3. The Structural Alteration of Low-Rank Coal in Low-Severity Liquefaction 20

4. Effects of Solvents and Catalyst Dispersion Methods in Temperature-Programmed Liquefaction

Tables 31

Figures 38 


\section{EXECUTIVE SUMMARY}

We have made significant progress in the following four aspects during this quarterly period: 1) influence of drying and oxidation of coal on the conversion and product distribution in catalytic liquefaction of Wyodak subbituminous coal using a dispersed catalyst; 2) spectroscopic characterization of dried and oxidized Wyodak coal and the insoluble residues from catalytic and thermal liquefaction; 3) the structural alteration of low-rank coal in low-severity liquefaction with the emphasis on the oxygen-containing functional groups; and 4) effects of solvents and catalyst dispersion methods in temperature-programmed and non-programmed liquefaction of three lowrank coals.

Effects of drying and mild oxidation on low-severity catalytic liquefaction were studied by using Wyodak subbituminous coal and ammonium tetrathiomolybdate (ATTM) as precursor to dispersed catalyst. The coal was dried under vacuum and in air at $100^{\circ} \mathrm{C}$ for various intervals of time and subjected to thermal and catalytic liquefaction at $350^{\circ} \mathrm{C}$. Raw coal was also liquefied under the similar conditions as a base line. Although a remarkably higher conversion is obtained in the thermal liquefaction of the raw coal compared to that of the vacuum and air-dried coal, it is an economic necessity to dry coal before liquefaction. Compared to the vacuum-dried coal, the coal dried in air at $100^{\circ} \mathrm{C}$ gave a better conversion in the presence of 1 -methylnaphthalene or tetralin in the catalytic runs. In the catalytic runs in presence of the solvents the raw coal did not show any improvement in conversion over the thermal runs but the dried coai showed a significant increase in the total conversion. Upon drying coal in air at $150^{\circ} \mathrm{C}$ for $20 \mathrm{~h}$ the total conversion significantly decreased to a lower value than that of the vacuum-dried coal. It seems that drying of coal in air to some extent of oxidation may be beneficial for liquefaction as compared to vacuum drying.

We also conducted a spectroscopic study of the coal drying and oxidation associated with catalytic liquefaction. Pyrolysis-GC-MS, CPMAS NMR and FTIR techniques were used to characterize Wyodak subbituminous coal before and after drying in vacuum and air and the residues from its thermal and catalytic liquefactions. The analysis of the air-dried coal shows a decrease in the phenolic and catechol-type structures in the coal network and increase in the ketone, carboxyl and ester groups as the oxidative drying proceeds. An enhanced decrease in the carbonyl structures is observed in the liquefaction residues from the raw coal as compared to that of the vacuum-dried coal. This may be due to the presence of water. The analysis of the liquefaction residues of the air dried coal show an increase in the ether linkages which may have a negative 
impact on liquefaction. The extent of the solvent adduction also increases during liquefaction with the extent of oxidation of coal.

The structural alteration of low-rank coal was studied for low-severity liquefaction. Hydrous pyrolysis experiments were performed on coalified wood to investigate the chemical transformations that occur in huminite (vitrinite) during low-temperature liquefaction. The dominant structural changes involve alteration of lignin structural units, initially by demethylation to form catechols, then by dehydration of the catechols to form aryl ether linkages. Further dehydration of these catechol structures involves the transformation to phenol and alkyl phenol structures that make up the macromolecular structure of the altered coalified wood. Experimental conditions varied with reaction times ranging from 30 minutes to 240 hours and temperatures ranging from $200^{\circ} \mathrm{C}$ to $350^{\circ} \mathrm{C}$. Structural characterization of the reacted residues was quantified by solid state ${ }^{13} \mathrm{C} \mathrm{NMR}$ and flash pyrolysis/gas chromatography/mass spectrometry. The combined analytical techniques show there is a progressive loss of oxygen which corresponds with the loss of catechols and guaiacols with increasing thermal stress. Dealkylation is also a dominant reaction pathway as revealed by a decrease in alkyl substituents in the residue. With a better understanding of the chemical reactions that transpire during the liquefaction of huminite, the dominant maceral in low-rank coals, better and more efficient reaction schemes can be employed to improve both the yields and products produced during liquefaction.

Effects of catalyst dispersion methods and influence of solvents were studied under temperature-programmed liquefaction (TPL) and single-stage liquefaction (SSL) conditions. For low-rank coals, such as Texas subbituminous, thermally initiated reactions can take place very rapidly at low temperatures, producing free radicals. These free radicals can either take the pathway of retrogressive reactions to form heavy materials or can be hydrogenated to form the desired light products. To find the optimum reaction conditions which can minimize the retrogressive reactions while enhancing hydrogenation, several reaction conditions such as singlestaged liquefaction (SSL) and temperature-programmed liquefaction (TPL) were compared. The effect of reaction solvents on the liqueraction was also studied using hydrogen-donor solvents (e.g. tetralin and decalin), a non-donor solvent (e.g. 1-methylnaphthalene) and a recycle solvent (Wilsonville middle distillate). Ammonium tetrathiomolybdate (ATTM) was chosen as the catalyst precursor. Three impregnation methods, including preswelling, incipient wetness and slurrying, were applied to investigate the effect of impregnation methods on the activity of the catalyst for liquefaction. 


\section{INTRODUCTION}

The conventional concept for high-severity conversion of coal is that coal must be heated to high temperatures $\left(400-450^{\circ} \mathrm{C}\right)$ causing thermal cleavage of bonds in organic matrix of coal to yield free radicals, which are capped by hydrogen to form low-molecular-weight products. However, recent fundamental research in coal liquefaction and pyrolysis has revealed that coal is more reactive than had been thought previously. The thermally initiated reactions of coal can take place very rapidly and, especially for low-rank coals, can occur at lower temperatures. We have performed the temperature-programmed pyrolysis (TPP) of different coals ranging from brown to bituminous coals, and the results clearly showed that more bonds in low-rank coals are thermally broken at lower temperatures as compared to bituminous coals, and a concept of bond energy distribution has been developed from TPP (Song et al., 1991a; Song and Schobert, 1992). Considerable prior work at Penn State (Davis et al., 1986, 1989; Derbyshire et al., 1986a, 1986b, 1989; Stansberry et al., 1987; Burgess and Schobert, 1990; Burgess et al., 1991) has demonstrated that the combination of low-temperature catalytic reaction followed by the high temperature catalytic reaction using dispersed molybdenum catalysts significantly enhanced coal conversion and oil production. More recent work in this laboratory has shown that temperatureprogrammed liquefaction using programmed heat-up is more effective for converting low-rank coals (Song et al., 1991b; Song and Schobert, 1992; Huang et al., 1992; Song et al., 1993). All these results point to the beneficial effects of reactions at lower temperatures as compared to conventional high-severity processes.

The above results strongly suggest that low-temperature catalytic pretreatment or preconversion is a promising approach and deserves further detailed study. This work is a fundamental study on effects of pretreatments on coal structure and reactivity in liquefaction. The main objectives of this project are to study the coal structural changes induced by low-temperature catalytic and thermal pretreatments by using spectroscopic technique;; and to clarify the pretreatment-induced changes in reactivity or convertibility of coals in the subsequent liquefaction. This report describes the recent progress of our work. 


\section{PROJECT OBJECTIVES}

This work is a fundamental study of catalytic pretreatments as a potential preconversion step to low-severity liquefaction. The ultimate goal of this work is to provide the basis for the design of an improved liquefaction process and to facilitate our understanding of those processes that occur when coals are initially dissolved. The main objectives of this project are to study the effects of low-temperature pretreatments on coal structure and their impacts on the subsequent liquefaction. The effects of pretreatment temperatures, catalyst type, coal rank and influence of solvent will be examined.

The specific objectives are to identify the basic changes in coal structure induced by catalytic and thermal pretreatments by using spectroscopic, thermochemical and chemical techniques; and to determine the reactivity of the catalytically and thermally treated coals for coal liquefaction. Combining the two lines of information will allow us to identify the pretreatment-induced desirable or undesirable basic changes in coal structure; to clarify the impacts of pretreatments on coal liquefaction; to identify the structures responsible for retrograde reactions; to evaluate the structural differences resulting from different catalytic actions in relation to the overall catalytic effects in liquefaction; and ultimately, to develop a structure-reactivity relationship for liquefaction associated with catalyst type, coal rank and solvent. Furthermore, this research will contribute greatly to the development of effective pretreatment procedures which will allow coals to be liquefied more efficiently than the current practice. Finally, much of the knowledge to be generated from this research is not only critical for developing advanced hydroliquefaction processes, but also very useful to development of coal/petroleum resid co-processing, pyrolysis and hydropyrolysis processes. 


\section{TECHNICAL PROGRESS}

\section{Influence of Drying and Oxidation of Coal on Coal Conversion and Products Distribution in Catalytic Liquefaction}

\section{INTRODUCTION}

Most of the subbituminous coals contain more then 25 wt $\%$ of moisture and it is considered an economic necessity to dry these coals prior to liquefaction. The drying of coal can have significant effect on the conversion reactivity of coal. Atherton (1) reported that the drying of low-rank subbituminous coal in a gas atmosphere did not effect the total conversion except in air. The air drying gave somewhat lower conversion, which may be a result of the adverse effect of preoxidation. The best conversion was obtained by vacuum and microwave drying. The oxidation of coal has been known to have an adverse effect on the coal conversion. Neavel (2) reported a significant reduction in the yield of benzene-soluble products from hvC bituminous coal as a result of oxidation. Cronauer et al. (3) reported that partial drying of subbituminous coal in a mixture of nitrogen and oxygen or even in nitrogen alone reduced the conversion as compared to that of the raw coal. On the other hand, Vorres et al. recently reported that drying can improve the oil yield in liquefaction of lignite samples (4)

In the present study we report the influence of drying Wyodak subbituminous coal in air and vacuum on the THF-conversion in thermal and catalytic liquefactions. From our results it appears that the drying of coal in air to some extent, which has been considered to be worse for liquefaction, may give a better conversion with dispersed Mo catalyst compared to the vacuumdried coal in the presence of a liquefaction solvent. The raw coal was also subjected to liquefaction. Best conversion was obtained from the raw coal in the thermal and catalytic solventfree run. In presence of solvents during catalytic runs the raw coal did not show any improvement over the thermal runs.

\section{EXPERIMENTAL}

The coal used was Wyodak subbituminous coal (DECS-8). This coal contains $32.4 \%$ volatile matter, $29.3 \%$ fixed carbon, $9.9 \%$ ash and $28.4 \%$ moisture, on as-received basis; $75.8 \%$ $\mathrm{C}, 5.2 \% \mathrm{H}, 1.0 \% \mathrm{~N}, 0.5 \% \mathrm{~S}$ and $17.5 \% \mathrm{O}$, on dmmf basis. The coal was dried under vacuum for $2 \mathrm{~h}$ at $100^{\circ} \mathrm{C}$. The drying of coal in air was done in an oven maintained at 100 and $150^{\circ} \mathrm{C}$ with 
the door partially open. At $100^{\circ} \mathrm{C}$ the coal was dried for 2,20 and 100 hours and at $150^{\circ} \mathrm{C}$ it was dried for 20 hours. The liquefaction was carried out at $350^{\circ} \mathrm{C}$ for 30 minutes under $7 \mathrm{MPa}$ (cold) $\mathrm{H}_{2}$ in $25 \mathrm{ml}$ tubing bomb. Ammonium tetrathiomolybdate (ATTM) was used as precursor for molybdenum sulfide catalyst. It was loaded onto coal by incipient wetness impregnation method from aqueous solution with $1 \mathrm{wt} \%$ Mo on dmmf basis. The impregnated coal samples were dried in a vacuum oven at $100^{\circ} \mathrm{C}$ for $2 \mathrm{~h}$. The experimental details about the liquefaction and the product work up is given elsewhere (5). The total conversion (TC) of the coal into soluble products has been calculated on the basis of the THF-insoluble residues. The analysis of the gases evolved during liquefactions at $350^{\circ} \mathrm{C}$ shows that the major components of the gases are $\mathrm{CO}$ and $\mathrm{CO}_{2}$. The total yield of the hydrocarbon gases produced is less than $1 \mathrm{wt} \% \mathrm{dmmf}$ coal, in all the liquefaction runs.

\section{RESULTS AND DISCUSSION}

\section{Solvent-free Liquefaction}

The products distribution for the solvent-free thermal liquefactions is given in Table 1.1. As compared to the vacuum-drying the air-drying of coal at $100^{\circ} \mathrm{C}$ for up to $100 \mathrm{~h}$ did not affect the total conversion on the basis of THF-insoluble residue. But the total gas yield increased with the drying time in air. This increase is mainly due to the increase in the $\mathrm{CO}$ and $\mathrm{CO}_{2}$ yields (Table 1.3) at the expense of other products, which is undesirable. The drying in air oxidizes the coal, increasing the carboxylic and carbonyl functionalities which upon thermolysis produce $\mathrm{CO}_{2}$ and $\mathrm{CO}$ gases. Upon excessive oxidation at $150^{\circ} \mathrm{C}$ for $20 \mathrm{~h}$ the coal conversion slightly decreased but the gas yield increased considerably, which was accompanied by the decrease in the oil, asphaltene and preasphaltene yields. Since the main constituent of the gas is $\mathrm{CO}_{2}$ which is associated with air-oxidation, it would be more appropriate to see the effect of drying on the desirable products. Figure 1.1 shows the distributions of the liquid and solid products in the solvent-free thermal liquefaction experiments. It is clear that compared to the vacuum drying, the air drying of coal at $100^{\circ} \mathrm{C}$ for up to $20 \mathrm{~h}$ increases the oil yield with no significant effect on the total conversion into THF-soluble products in thermal runs. But oxidative drying for the extended period of time decreases the total conversion as well as the oil yield because of the extensive degradation of the coal.

As with the vacuum-dried coal, the presence of catalyst in the solvent-free runs of the airdried coal increases the total conversion compared to that of the thermal runs on the basis of THFinsoluble residues (Table 1.2). Similar to the thermal runs, in catalytic liquefactions the drying of 
coal in air at $100{ }^{\circ} \mathrm{C}$ for up to $100 \mathrm{~h}$ does not show any significant effect on the total conversion as compared to that of the vacuum-dried coal. The gas yields in the catalytic runs are lower than in the corresponding thermal runs with the most contribution from $\mathrm{CO}_{2}$ and also increases with the drying time. If the conversion is calculated excluding the gas yield, the air-dried coal at $100^{\circ} \mathrm{C}$ for up to $20 \mathrm{~h}$ does not show any effect but for the drying time of $100 \mathrm{~h}$ and at $150^{\circ} \mathrm{C}$ for $20 \mathrm{~h}$ there is a considerable decrease in the conversion compared to that of the vacuum-dried coal (Figure 1.1). Overall, the increase in total conversion for the air-dried coal in catalytic runs over the thermal runs is similar to that for the vacuum-dried coal (Table 1.2 and Figure 1.1).

As-received coal (raw) was also subjected to thermal and catalytic liquefactions. The products distribution is given in Tables 1.1 and 12 . Surprisingly, best values for the total conversions are obtained in the solvent-free thermal $(25.0 \mathrm{wt} \%)$ and catalytic $(43.3 \mathrm{wt} \%)$ runs on the basis of THF-insoluble residue compared to the vacuum- (12.5 and $29.8 \mathrm{wt} \%$, respectively) and air-dried coal (14.8 and $29.2 \mathrm{wt} \%$, respectively, for $2 \mathrm{~h}$ drying time). Significant increase in the oil yield is also observed from the raw coal compared to the dried coal. There is also a higher gas yield from the raw coal in thermal run compared to the vacuum- and air-dried coal at $100{ }^{\circ} \mathrm{C}$ for up to $20 \mathrm{~h}$ (Table 1.3). The increase in the gas yield is mainly due to the remarkable increase in the $\mathrm{CO}$ and $\mathrm{CO}_{2}$ yields. The increase in the $\mathrm{CO}$ and $\mathrm{CO}_{2}$ gases is due to the presence of water in the coal. It has been reported that the presence of water in the oxidized coal may enhance the removal of oxygen-containing groups (6). It appears that the presence of water during liquefaction removes the carbonyl functionalities from the coal network which makes the coal less refractory for liquefaction and hence improved conversion. The total conversions, excluding the gas yield shown in Figure 1.1, are the best in the case of the raw coal both in the solvent-free thermal and catalytic runs.

\section{Liquefaction in Presence of Tetralin}

It is known that the presence of a hydrogen donor solvent during liquefaction enhances the total conversion of a coal to THF-soluble products as compared to the solvent-free runs. In the presence of tetralin during thermal runs the increase in total conversion of the vacuum-dried and air-dried coal is quite remarkable but, relatively, air-dried coal shows more increase in conversion (Table 1.1 and 1.2). The vacuum-dried coal shows an increase of $13.4 \%$ (12.5\% excluding gas yield) while the total conversion for the air-dried coal for $2 \mathrm{~h}$ at $100{ }^{\circ} \mathrm{C}$ increases by $20.3 \%$ (19.9\% excluding gas yield). The coal dried in air for 20 and $100 \mathrm{~h}$ at $100^{\circ} \mathrm{C}$ also shows a remarkable increase in conversion in the presence of tetralin but the increase is not as much as for the coal dried for $2 \mathrm{~h}$. The oil yield for the air-dried coal for $2 \mathrm{~h}$ at $100^{\circ} \mathrm{C}$ increases from $3.3 \%$ to 
$11.7 \%$ with an increase of $8.4 \%$ in presence of tetralin, correspondingly, the increase in the oil yield for the vacuum-dried coal is only $2.0 \%$. The oil yield for the coal dried at $100^{\circ} \mathrm{C}$ in air for 20 $h$ is also better than that of the vacuum-dried coal. The increase in the asphaltene and preasphaltene yields in presence of tetralin as compared to that of the solvent-free runs for the air-dried for $2 \mathrm{~h}$ and vacuum-dried coal are not significantly different. As the coal was dried in air for longer periods of time at $100^{\circ} \mathrm{C}$ the increase in the oil production declined. The coal dried in air for $20 \mathrm{~h}$ at $150^{\circ} \mathrm{C}$ showed only an increase of $1.5 \%$. These results show that in thermal runs with tetralin the air-dried coal at $100^{\circ} \mathrm{C}$ for up to $20 \mathrm{~h}$ gives better conversion and oil yield compared to the vacuum-dried coal (Figure 1.2). This suggests that the oxidation of a coal to some extent may enhance the oil yield and the total conversion but excessive oxidation of coai may have a negative effect.

The total conversion for the raw coal is $43.3 \%$ (37.5\%, excluding gases) in thermal liquefaction in the presence of tetralin (Table 1.1). This conversion is undoubtedly better than the air-dried or vacuum-dried coal runs. Raw coal liquefaction gives an oil yield of $15.8 \%$ with an increase of $10.4 \%$ over the solvent-free run. Increasing the oil yields in liquefaction experiments is most desirable. Compared to the air-dried or vacuum-dried coal the oil yield is better in the case of raw coal run (Figure 1.2).

In the catalytic liquefactions also there is a remarkable increase in the total conversion from that of the solvent-free runs in presence of tetralin. This increase is similar to that in the thermal runs for the air-dried coal at $100^{\circ} \mathrm{C}$ and vacuum-dried coal (Tables 1.1 and 1.2). In the catalytic runs in presence of tetralin the air-dried coal at $100^{\circ} \mathrm{C}$ gives better total conversion compared to the vacuum-dried coal, on the basis of THF-insoluble or the total yields of oil, asphaltene and preasphaltene (Table 1.2 and Figure 1.2). It seems that the extent of drying at $100^{\circ} \mathrm{C}$ also does not decrease the total conversion. Unexpectedly, the liquefaction of the raw coal in presence of tetralin does not show any significant catalytic improvement in total conversion (Figure 1.2). In the catalytic liquefaction in presence of tetralin of the raw coal the total conversion is $42.2 \%(39.4 \%$ excluding gas yield) and is $43.3 \%$ (37.5.\% excluding gas yield) in the thermal runs with tetralin. The products distribution of the raw coal experiments are also quite similar. As seen before in the thermal runs, the raw ccal showed a remarkably higher conversion in presence of tetralin, compared to the air-dried coal (Table 1.1). In the catalytic runs the raw coal and the air-dried coal showed very similar conversions (Table 1.2 and Figure 1.2). It seems that during liquefaction of the raw coal in presence of tetralin the catalyst is less active. The decrease in the $\mathrm{H}_{2}$ consumption by the raw coal during catalytic liquefaction in presence of tetralin from that in the solvent-free run is much higher then that for the dried coal (Figure 1.4). 
Liquefaction in the Presence of 1-Methylnaphthalene

It has been seen before that the presence of a non-donor solvent such as 1 methylnaphthalene (1-MN) also enhances the total conversion to some extent compared to that of the solvent-free runs. In the thermal liquefaction of the vacuum-dried coal the total conversion increases from $12.5 \%$ in the solvent-free run to $18.3 \%$ with $1-\mathrm{MN}$ (Table 1.1). The difference is significantly high. The liquefaction of the air-dried coal in presence of 1-MN also shows a considerable increase as compared to that of the solvent-free runs. Total conversions for the coal dried at $100{ }^{\circ} \mathrm{C}$ for 2 and $20 \mathrm{~h}$ in air increase from 14.8 and $15.5 \%$ to 22.4 and $24.1 \%$ respectively, in presence of $1-\mathrm{MN}$. These conversion figures are better than that of the vacuumdried coal (Table 1.1). Even after excluding the gas yields, the conversion is better if the coal was dried at $100^{\circ} \mathrm{C}$ for up to $20 \mathrm{~h}$ in air. (Figure 1.3). Upon drying coal for $100 \mathrm{~h}$ at $100{ }^{\circ} \mathrm{C}$ in air the total conversion decreases and it is worse for the extensively oxidized coal at $150^{\circ} \mathrm{C}$ for $20 \mathrm{~h}$.

The total conversion of the raw coal in the thermal liquefaction increases from $25.0 \%$ (17.3\% excluding gas) in solvent-free run to $39.9 \%$ (34.0\%, excluding gas) with 1-MN (Table 1.1). This increase is significantly higher than that of the air- or vacuum-dried coal. In the thermal runs with $1-\mathrm{MN}$ the raw coal gives $19.7 \%$ more THF-soluble products excluding gas yield, compared to the vacuum-dried coal, which is remarkably higher than that of the air-dried coal. Most importantly the increase in the total conversion of the raw coal is due to the significant increase in the yield of the most desirable product, oil. The oil yield increases from $1.1 \%$ in the vacuum-dried coal to $15.9 \%$ in the raw coal.

The catalytic liquefaction of vacuum- or air-dried coal in presence of $1-\mathrm{MN}$ improves the conversion. The best conversion is obtained in the case of air-dried coal at $100^{\circ} \mathrm{C}$. The extent of drying at this temperature does not seem to make any considerable difference in the conversion (Table 1.2 and Figure 1.3). The catalytic liquefaction of the raw coal in presence of 1-MN gives a total conversion of $35.9 \%$ on the THF-insoluble residue basis. This conversion is rather lower than that of the thermal liquefaction under similar conditions. The unusual decrease in the oil yield for the raw coal in the catalytic run compared to that in the thermal run may be an artifact which needs to be reconfirmed. As in the presence of tetralin, during the liquefaction of the raw coal in the presence of $1-\mathrm{MN}$ in the catalytic runs there is no improvement in the total conversion compared to the thermal runs. In the catalytic liquefaction in presence of $1-\mathrm{MN}$ the best conversion obtained is with the coal dried in air at $100^{\circ} \mathrm{C}$ with a significantly higher oil yields compared to the vacuum-dried coal. 


\section{Hydrogen Consumption}

Figure 1.4 shows the $\mathrm{H}$-consumption profile for the thermal and catalytic liquefactions from $\mathrm{H}_{2}$ gas and from tetralin. There is a significant decrease in the $\mathrm{H}_{2}$ consumption during thermal liquefaction if the coal is pre-dried. In the solvent-free thermal run the $\mathrm{H}_{2}$ consumption increases with the drying time in air at $100^{\circ} \mathrm{C}$ and also the consumption increases as the coal is dried at $150^{\circ} \mathrm{C}$ for $20 \mathrm{~h}$. With tetralin and $1-\mathrm{MN}$ there is an initial decrease in the $\mathrm{H}_{2}$ consumption from $2 \mathrm{~h}$ to $20 \mathrm{~h}$ drying time and than it increases with the increased oxidative drying of coal. This suggests that the oxidative drying of coal increases the $\mathrm{H}_{2}$-consumption during liquefaction and the consumption is higher if no solvent is used. In the catalytic runs the oxidative drying of coal at $100^{\circ} \mathrm{C}$ for up to $100 \mathrm{~h}$ does not seem to have any significant effect on $\mathrm{H}_{2}$ consumption. When the coal is dried at $150^{\circ} \mathrm{C}$ for $20 \mathrm{~h}$ a slight decrease in the $\mathrm{H}_{2}$ consumption in the solvent-free catalytic liquefaction is observed otherwise in presence of a solvent the $\mathrm{H}_{2}$ consumption is essentially the same. These results suggest that the $\mathrm{H}_{2}$ consumption increases with the extent of oxidation in thermal liquefaction and in catalytic liquefactions the oxidation does not make any considerable difference.

The vacuum-dried coal shows a similar $\mathrm{H}_{2}$ consumption value as that of the coal dried in air for $2 \mathrm{~h}$ in thermal is well as catalytic runs. But during thermal liquefaction of the raw coal the $\mathrm{H}_{2}$ consumption is higher than that of the vacuum- and air-dried coal for $2 \mathrm{~h}$. In the catalytic liquefaction of the raw coal in presence of solvents the $\mathrm{H}_{2}$ consumption is not much different from that of the vacuum- or air-dried coal for $2 \mathrm{~h}$, but in the solvent-free catalytic run the $\mathrm{H}_{2}$ consumption is remarkably higher. These results may account for the better conversions in the case of raw coal liquefaction compared to that of the vacuum- or air-dried coal.

Hydrogen transfer from tetralin (Figure 1.4) increases (in the thermal liquefactions) with the extent of oxidation of coal. Vacuum-dried and the raw coal show a lower H-transfer compared to that of the air-dried coal. In the catalytic runs the $\mathrm{H}$-transfer from tetralin is relatively lower than that in the corresponding thermal run and does not make any noticeable difference as the coal is dried at $100{ }^{\circ} \mathrm{C}$ in air up to $100 \mathrm{~h}$. When the coal is dried at $150^{\circ} \mathrm{C}$ for $20 \mathrm{~h}$ the $\mathrm{H}$-transfer is slightly higher. The vacuum-dried coal shows the lowest value for the $\mathrm{H}$-transfer from tetralin in the catalytic run. 


\section{CONCLUSIONS}

The air-dried coal at $100^{\circ} \mathrm{C}$ for up to $20 \mathrm{~h}$ gave similar conversions as the vacuum-dried coal in the solvent-free thermal and catalytic liquefactions. In the presence of solvents, better conversions were obtained from the coal dried in air at $100^{\circ} \mathrm{C}$ for $2 \mathrm{~h}$ compared to the vacuumdried coal. The extensive oxidation of coal decreased the coal conversions in thermal as well as catalytic runs. These results suggest that air drying of coal to some extent may be beneficial for liquefaction. The ra 7 coal gave the best conversions in the solvent-free runs. The improved conversion seems to be due to the presence of water, which enhances the removal of carbonyl functionalities during liquefaction, making the coal network less refractory for liquefaction.

\section{REFERENCES}

1. Atherton, L.F.; Proc. 1985 Int. Conf. Coal Sci., p.553.

2. Neavel, R.; Fuel 1976, 55, 237.

3. Cronauer, D.C., Ruberto, R.G., Silver, R.S., Jenkins, R.G., Davis, A., and Hoover, D.S.; Fuel, 1984, 63, 77.

4. Vorres, K.S., Wertz, D.L., Malhotra, V., Dang, Y., Joseph, J.T., and Fisher, R.; Fuel, 1992, 71, 1047.

5. Saini, A.K., Song, C., Schobert, H.H., and Hatcher, P.G.; ACS Fuel Chem. Div. Prepr. 1992, 37(3), 1235.

6. Petit, J.C.; Fuel, 1991, 70,1053.

2. Characterization of Dried and Oxidized Coal and the Insoluble Residues from Their Catalytic and Thermal Liquefaction

\section{INTRODUCTION}

Because of the high moisture content of the low-rank coals it is desirable to dry coal before liquefaction. It has been recognized that drying of coal could adversely affect the reactivity of subbituminous coal for liquefaction $(1,2)$. This study has been carried out with a view to understand the effect of low-temperature oxidative and non-oxidative drying on coal structure and 
liquefaction residues. In the preceding section the impacts of coal drying on the liquefaction have been discussed (3).

Several papers have been devoted to understanding the oxidation of coal (4-10) but very little has been reported on the effect of oxidation on the structures of liquefaction residues, which could lead to an insight of the oxidative effect on liquefaction. In the present work we have analyzed the residues from thermal as well as catalytic liquefactions of the raw and coal dried under vacuum and in air. The analysis of the residues reveals that although there is a significant decrease in the aliphatics upon oxidative drying of coal compared to the vacuum-dried coal, the residues from the air-dried coal are more aliphatic-rich, and as the oxidation proceeds more longer-chain aliphatics are lost during liquefaction. The raw coal shows an enhanced loss of carbonyls during liquefaction, which may be the cause of its higher conversion.

\section{EXPERIMENTAL}

The coal used was Wyodak subbituminous obtained from the Penn State Sample Bank (DECS-8). The characteristics of coal are given elsewhere (11). For the raw coal liquefaction it was used as received. For the drying experiments the coal was dried under vacuum at $100^{\circ} \mathrm{C}$ for 2 $\mathrm{h}$ and in air at $100^{\circ} \mathrm{C}$ for 2,20 and $100 \mathrm{~h}$. At $150^{\circ} \mathrm{C}$ coal was dried for $20 \mathrm{~h}$. The air drying of coal was done in a preheated oven at desired temperature with the door slightly open to ensure a sufficient air supply. The thermal and catalytic liquefactions of coal were carried out at $350^{\circ} \mathrm{C}$ under $6.9 \mathrm{MPa}$ (cold) $\mathrm{H}_{2}$ pressure for 30 minutes. Ammonium tetrathiomolybdate (ATTM) was used as catalyst precursor. It was loaded on to coal by incipient wetness impregnation method from aqueous solution, with $1 \mathrm{wt} \%$ Mo on dmmf coal. After the reaction, the liquid and solid products were separated by sequential extraction with hexane, toluene and THF. After the extraction the THF-insoluble residu were washed first with acetone and then pentane in order to remove all the THF, followed by di ing at $110^{\circ} \mathrm{C}$ for $6 \mathrm{~h}$ under vacuum. The coal and residues were analyzed by Py-GC-MS, solid state CPMAS ${ }^{13} \mathrm{C}$ NMR and FTIR techniques discribed elsewhere $(12,13)$.

\section{RESULTS AND DISCUSSION}

\section{Characterization of the Raw and Dried Coal}

CPMAS ${ }^{13}$ C NMR 
Figure 2.1 compares the CPMAS ${ }^{13} \mathrm{C}$ NMR spectra of the raw coal and the vacuum and air-dried coal. The raw coal and the dried coal show similar NMR features. The region between 0-80 ppm consists of aliphatic carbons, which may include methoxy carbons, and the second region between 90 to $170 \mathrm{ppm}$ is due to the aromatic carbons, including two shoulders due to catechol-like and phenolic carbons (11). The carboxylic band appears at 170-190 ppm and carbonyl group between 190-230 ppm. Upon drying coal under vacuum there was no noticeable difference in the NMR spectrum as compared to that of the raw coal. When the coal was dried in air a slight difference seems to be apparent, but not very significant until the coal was dried at 100 ${ }^{\circ} \mathrm{C}$ for $100 \mathrm{~h}$ or at $150^{\circ} \mathrm{C}$ for $20 \mathrm{~h}$. It appears that as the coal was dried under oxidative conditions there was a decrease in the intensity of the catechol shoulder. The other change seems to be the 'Jroadening in the carboxyl and carbonyl bands. These changes in the coal structure become apparent when the coal was dried in air under severe conditions. After drying coal at $150^{\circ} \mathrm{C}$ for 20 $\mathrm{h}$ the CPMAS ${ }^{13} \mathrm{C}$ NMR shows a complete disappearance of the catechol peak and the carboxyl and carbonyl peaks also show significant broadening, and seem to be merging into the aromatic band. The oxidation of coal significantly decreases the aliphatics from the coal. From NMR the decrease in aliphatics is not apparent when coal is dried at $100^{\circ} \mathrm{C}$, but after drying at $150^{\circ} \mathrm{C}$ the aliphatic band shows a significant decrease.

\section{FTIR}

An obvious difference in the FTIR spectrum of the dried coal compared to that of the raw coal is the decrease in the broad water band between $3000-3600 \mathrm{~cm}^{-1}$, which is apparent from the direct comparison of the spectra. The drying of coal in air is known to oxidize the coal, causing increase in the ketone, carboxy! and ester type functionalities and decrease in the aliphatic groups. Such changes in the functionalities of the coal upon oxidation at $100^{\circ} \mathrm{C}$ were not apparent from direct comparison of the spectra. The difference FTIR technique was utilized to detect the minute spectroscopic changes in the coal structure. Vacuum-dried coal was used as a reference for the difference spectra. The differences in coal structure arising due to oxidative drying of coal apparent from the difference FTIR spectra are consistent with the literature (4-10). The difference spectra show a prominent peak at $1720 \mathrm{~cm}^{-1}$ due to carbonyl, which increases in intensity with the severity of drying. There is another shoulder on the high-energy side of the $1720 \mathrm{~cm}^{-1}$ band near $1770 \mathrm{~cm}^{-1}$ which also increases with the severity of drying. This band could be assigned to the ester groups. The band at $1640 \mathrm{~cm}^{-1}$ in the difference spectra can be assigned to the highly conjugated carbonyls formed by the oxidation of the methylene bridges linking aromatic units (Ar$\mathrm{CH}_{2}$-Ar), which are highly susceptible to autoxidation, forming Ar-CO-Ar groups. As the oxidative drying at $100{ }^{\circ} \mathrm{C}$ proceeds, the band at $1720 \mathrm{~cm}^{-1}$ due to carboxyl carbonyls seems to be 
increasing at a faster rate than $1640 \mathrm{~cm}^{-1}$ band. This band may also contain carbonyls in unconjugated ketones. After drying coal at $150^{\circ} \mathrm{C}$ for $20 \mathrm{~h}$ in air the $1720 \mathrm{~cm}^{-1}$ band becomes inore intense relative to the $1640 \mathrm{~cm}^{-1}$ band. A broad band between 1500 and $1590 \mathrm{~cm}^{-1}$ also becomes apparent in the difference spectra of the dried coal. This band is assigned to the carboxylate (COO-) groups, which increase upon oxidative drying of coal. After drying coal at $150^{\circ} \mathrm{C}$, the broad band at $1550 \mathrm{~cm}^{-1}$ in the difference spectrum due to the carboxylate carbonyls (-COO-) which is just a broad shoulder in the case when coal was dried at $100^{\circ} \mathrm{C}$, becomes an independent peak. The increase in the intensity of the $1550 \mathrm{~cm}^{-1}$ band could be related to the increase in the carboxylic functional groups upon oxidation followed by exchange with cations present in the coal to give COO- The region between the range 1000 and $1300 \mathrm{~cm}^{-1}$ consists of the bands due to $\mathrm{C}-\mathrm{O}$ type of linkages in ethers, esters and phenols. Upon oxidative drying at 100 ${ }^{\circ} \mathrm{C}$ there is a slight increase in the intensity of the ether region.

\section{Pyrolysis-GC-MS}

The major aromatic components of Wyodak subbituminous coal obtained upon pyrolysis have been reported previously (3). Low-rank coals are known to have higher oxygen functionalities. The major oxygen compounds are phenol, methylphenol, ethylphenol, $\mathrm{C}_{2}$-phenols and catechol, and these are the most abundant components in the pyrogram of the raw coal. Among the alkylbenzenes the most abundant compounds identified are toluene, xylenes and $\mathrm{C}_{3}$ benzenes. The other aromatic compounds such as naphthalene and alkyl naphthalenes are also found but in very low concentrations. There are many other peaks appearing over the whole pyrogram of the raw coal. These peaks have been identified as alkanes and alkenes ranging from C4-C31. The most abundant of these are $\mathrm{C}_{4}-\mathrm{C}_{6}$ alkanes and alkenes which appear in the early part of the pyrogram and are not very well resolved.

Upon drying coal under vacuum or in air the pyrogram is similar to that of the raw coal in which one can find identical peaks. The only difference is in the relative intensities of the peaks. Table 2.1 shows the ratios between the total area of the major phenolic and the alkylbenzene compounds in the pyrograms of the raw and the dried coal samples. The vacuum drying of coal did not change the phenolics-to-alkylbenzene ratio but oxidative drying of coal seems to have a significant effect on these ratios. For first two hours of drying coal in air at $100^{\circ} \mathrm{C}$ the change is not very significant, but as the extent of drying increases the ratio seems to be decreasing as if the phenolic structures are being consumed from the coal as the air-drying proceeds. After drying coal at $150^{\circ} \mathrm{C}$ for $20 \mathrm{~h}$ the phenolic-to-alkylbenzene ratio decreases remarkably. 
Using the selective ion chromatogram (SIC) technique for the $71 \mathrm{~m} / \mathrm{z}$ ion the pattern of the abundances of the alkanes and alkenes can be recognized in the pyrogram of the coal. The SIC for the raw and the vacuum-dried coal using $71 \mathrm{~m} / \mathrm{z}$ ion show a similar pattern. The most abundant are the $\mathrm{C}_{4}-\mathrm{C}_{6}$ alkanes and alkenes. Upon air drying, coal shows a decrease in the intensities of the short-chain aliphatic compounds. The extent of air drying did not change the overall pattern of the aliphatics; the SIC of aliphatics for all the air-dried samples looked similar.

\section{Characterization of the Liquefaction Residues}

FTIR

To investigate the differences in the structure of the residues from the raw and air-dried coal and to understand the liquefaction behavior of the coal dried under different conditions, the residues from the vacuum-dried coal were used as reference for the FTIR difference spectra. The spectra of vacuum-dried coal residues were subtracted from those of the raw and the air-dried coal. The subtraction factors were calculated on the basis of the amount of organic matter left in the residues after liquefactions and calculated by the ratio of the amount of dmmf coal per mg of the pellet, keeping the diameter of the pellet constant. Before discussing the differences in coal structure using the difference technique, it should be noted that the frequencies of the bands in the difference spectra are not well defined and also the apparent frequencies of different bands can often be affected by the degree of subtraction and residual band overlap (8).

The difference spectra of the residues from the thermal runs show a significant difference in the coal structure as a consequence of air drying (Figure 2.2-1.4). The major differences are in the carbonyl region (1500-1800 cm-1). The raw coal shows a negative band at $1740 \mathrm{~cm}^{-1}$ which could be assigned to the ester and ketone groups. This band is negative also in the case when tetralin or 1-methylnaphthalene was used as solvent, suggesting that during liquefaction the raw coal loses more of carbonyl structures compared to the vacuum-dried coal. The enhanced loses of carbonyls from the raw coal can also be accounted by the relative increase in the $\mathrm{CO}_{2}$ and $\mathrm{CO}$ gas yields compared to the vacuum-dried coal. The residues from the air-dried coal also show a significantly higher loss of ester groups as indicated by the negative dip in the ester region of the difference spectra. But, there is also a positive band at $1700 \mathrm{~cm}^{-1}$ which could be assigned to the carboxylic groups. The carboxylic band increases with the extent of oxidation. The increase in the carboxylic functionalities in the residues could also be noticed by the broad band centered at 1590

$\mathrm{cm}^{-1}$. This band is assigned to the carboxylate (COO-) groups. The increase in these 
functionalities is the consequence of increase in the carboxylic groups upon oxidation of coal. This band may also have slight contribution from the aromatic $\mathrm{C}=\mathrm{C}$ stretching which appears at 1610 $\mathrm{cm}^{-1}$.

In the aliphatic region between $2700-2950 \mathrm{~cm}^{-1}$ the raw coal shows no significant change in the band (Figure 2.2-2.4). But, relative to the vacuum-dried coal, the residues from the airdried coal show a significantly higher aliphatic content shown by the positive aliphatic bands. This is only true when coal was dried in air at $100^{\circ} \mathrm{C}$, but for the coal dried at $150{ }^{\circ} \mathrm{C}$ for $20 \mathrm{~h}$ the aliphatic region shows a negative change. The increase in the aliphatics in the residues from air drying at $100{ }^{\circ} \mathrm{C}$ is intere ting because the unreacted air-dried coal shows a decrease in the aliphatics because of the oxidation of some of the aliphatic groups. It appears that, during liquefaction, the air-dried coal at $100{ }^{\circ} \mathrm{C}$ has retained more of the aliphatic components of the network as compared to those of the vacuum-dried coal. The negative aliphatic band in the case of the coal dried at $150^{\circ} \mathrm{C}$ could be due to the extensive loss of these groups initially during air drying. In the presence of tetralin or 1-MN also the air-dried coal showed an increase in the aliphatics.

The same criteria were adopted, as for the thermal runs, to obtain the FTIR difference spectra for the residues from the catalytic runs. Compared to the thermal runs, the difference spectra for the catalytic runs did not show any significant differences. Similar to the thermal runs, the residues from the air-dried coal at $100{ }^{\circ} \mathrm{C}$ were found to be more aliphatic and carbonyl-rich compared to the vacuum-dried coal. The residues from the tetralin and $1-\mathrm{MN}$ runs also showed similar difference spectra, except that the raw coal seemed to be more aliphatic-rich in the catalytic runs.

More significant differences in the thermal and catalytic runs were observed when the difference spectra were obtained between the residues from thermal and catalytic runs (Figure 2.52.7). The FTIR spectra of the catalytic runs were subtracted from those of the thermal runs. The negative mineral matter bands $\left(1010\right.$ and $\left.1035 \mathrm{~cm}^{-1}\right)$ in the difference spectra of the thermal and catalytic runs are the signs of greater conversion of coal during catalytic runs. In the case of the raw coal the mineral matter bands are negative only in the solvent-free runs which may be because in the presence of solvents the raw coal did not show any significant difference in conversions between thermal and catalytic runs. The negative aliphatic bands in the difference spectra of the solvent-free runs clearly showed that during thermal runs more aliphatic compounds were lost in all the cases except when coal was oxidized at $150{ }^{\circ} \mathrm{C}$. The differences in the aliphatic contents in the solvent runs were not very clear, probably due to the differences in the adduction of solvents 
during liquefaction. In the carbonyl region positive bands near 1700 and $1550 \mathrm{~cm}^{-1}$ were observed in the solvent-free as well as solvent runs. The first band could be due to ketone and carboxylic groups and the second band could be assigned to the carboxylate ions. This suggests that the residues from the thermal runs are richer in such functionalities. The ether region between $1100-1300 \mathrm{sm}^{-1}$ also showed significantly intense positive bands which clearly suggests that more of ether-type bonds are broken during catalytic liquefaction compared to the thermal runs. At the high oxidation level the ether region did not show any noticeable difference in the ether contents of the thermal and catalytic residues. The most significant difference was observed for the coal dried at $100^{\circ} \mathrm{C}$.

\section{Pyrolysis-GC-MS}

Compared to the raw coal, the residues from the thermal solvent-free liquefactions show similar pyrolysis compounds; that is one can identify the same compounds in the raw coal as well as in residues. The differences in the pyrograms appear to be in the relative abundances of the compounds. Table 2.1 gives the ratios between phenolic and alkylbenzene compounds. For these ratios, same compounds have been used as for the raw coal mentioned above. These ratios indicate the variations in the chemical composition of the aromatic compounds in the coal network as a consequence of different treatments of coal. After solvent-free thermal liquefaction of the raw coal the phenolic-to-alkylbenzene ratio decreases remarkably compared to that of the unreacted coal. Similar decrease is observed for the air-dried coal at $100^{\circ} \mathrm{C}$ for $2 \mathrm{~h}$ and the vacuum-dried coal. For the coal dried at $100^{\circ} \mathrm{C}$ for 20 and $100 \mathrm{~h}$ and dried at $150{ }^{\circ} \mathrm{C}$ there is no significant change in this ratio. From the catalytic solvent-free liquefaction the phenolic-to-alkylbenzene ratios of the residues are slightly higher than that of the corresponding residue from the thermal run, but they are still lower than that of the unreacted coal. It appears that as the oxidative drying proceeds the difference in the phenolic-to-alkylbenzene ratio between the unreacted coal and the liquefaction residue decreases. Eventually at extensive oxidation of coal this ratio becomes the same for the unreacted coal and its liquefaction residue.

Figure 2.8 compares the pattern of the aliphatics present in the pyrogram of the residues from solvent-free thermal runs. Noticeable differences can be seen in the relative intensities of the aliphatics compared to that of the corresponding unreacted coal. In the residues from the raw and vacuum-dried coal there is an appreciable decrease in the intensities of the shorter chain relative to the longer chain aliphatics, which has been noticed before with different coals. For the air-dried unreacted coal, as mentioned before, the pattern of the aliphatics in the pyrogram remains similar with the extent of drying, but for the residues the pattern is quite different. By comparing the 
residues from the air-dried coal at different extents of oxidation it appears that as the extent of oxidation increases more and more of longer chain aliphatics are lost during thermal liquefaction (Figure 2.8). It seems that for the air-dried coal the shorter chain aliphatics are strongly retained upon liquefaction. This phenomenon was not observed for the catalytic runs.

All the pyrolysis compounds found in the pyrogram of the raw coal can also be identified in the pyrograms of the residues from the liquefactions in presence of solvents. There are several new bands which are known to have come from the the adduction of solvent used during liquefaction (11). Some of these compounds are in large abundances. From the liquefaction runs in presence of tetralin the peaks due to the solvent are tetralin, dihydronaphthalene, naphthalene and 1- and 2-methylnaphthalenes. $\mathrm{C}_{2}$-naphthalenes may also be due to tetralin but are in very low abundances. From the runs with 1-methylnaphthalene two solvent adduction bands are observed, naphthalene and 1-methylnaphthalene. In our previous work (11) we reported that the adduction of solvents could be either due to the formation of chemical bonds between the solvent molecules and coal network or the solvent molecules could be physically entrapped in the micropores. From Figure 5 the adduction of solvent is apparent by the presence of tetralin, dihydronaphthalene, naphthalene and 1- and 2-methylnaphthalene peaks. It is clear that the extent of adduction of the solvents is remarkably effected by the extent of initial oxidation of the coal. Apparently, as the oxidation proceeds the relative intensities of the adducted compounds increases. A similar trend was observed in the case when 1-MN was used as solvent. The residues from the catalytic runs also show similar trends in the adduction of solvents with the drying of coal, but during catalytic runs the adduction seems to be lower as compared to the thermal run.

Not much difference is observed between the pyrograms qualitatively in Figure 2.9. All the pyrograms for the raw and dried coal under different conditions have the same compounds, but there relative intensities are significantly different. Figure 2.1 gives the phenolic-to-alkylbenzene ratios. These ratios have increased significantly for residues from the raw coal and for the coal dried in air at $100^{\circ} \mathrm{C}$ for $2 \mathrm{~h}$ and under vacuum, compared to that of the solvent-free runs. But, for the $1-\mathrm{MN}$ runs these ratios seem to be similar to those of the thermal runs. It seems that during solvent-free runs or in the presence of 1-MN more phenolic-type units, which produce phenolic compounds upon pyrolysis, are lost. This phenomena seems to be true for raw, vacuum-dried coal and for the coal dried in air at $100{ }^{\circ} \mathrm{C}$ for $2 \mathrm{~h}$. At the higher oxidative drying of coal the change in the ratios of the phenolic-to-alkylbenzene is not significant. 


\section{CONCLUSIONS}

The characterization of the liquefaction residues reveals that the residues from the air-dried coal are more aliphatic and carbonyl-rich compared to the vacuum-dried coal. The increase in the carbonyls is due to the oxidation of the coal upon air drying. It appears that upon oxidation of coal at $100^{\circ} \mathrm{C}$ more shorter chain aliphatics are retaired in the coal network as compared to the vacuumdried coal. The enhanced conversion of the unoxidized raw coal may be due to the enhanced loss of carbonyls upon reacting with water. The enhanced loss of carbonyls with water can make coal less refractory for liquefaction. The Py-GC-MS analysis of the residues suggests that the extent of oxidation can enhance the solvent adduction during liquefaction.

\section{REFERENCES}

1. Cronauer, D.C., Ruberto, R.G., Silver, R.S., Jenkins, R.G., Davis, A., and Hoover, D.S.; Fuel, 1984, 63, 71-77.

2. Atherton, L.F.; Proc. 1985 Int. Conf. Coal Sci., p.553.

3. Saini, A.K., Song, C., and Schobert, H.H.; ACS Fuel Chem. Prepr., 1993, 38 (2), 593.

4. Cronauer, D.C., Ruberto, R.G., Jenkins, R.G., Davis, A., Painter, P.C., Hoover, D.S.; Starsinic, M.E., and Schlyer, D.; Fuel, 1983, 62, 1124-1132..

5. Calemma, V., Iwanski, P., Rausa, R., and Girardi, E.; ACS Fuel Chem. Prepr. 1992, 730 .

6. Calemma, V., Rausa, R., Margarit, R., and Girardi, E.; Fuel, 1988, 67, 764.

7. Clemens, A.H., Matheson, T.W., and Rogers, D.; Fuel, 1991, 70, 215.

8. Rhoads, C.A., Senftle, J.T., Coleman, M.M., Davis, A., and Painter, P.C.; Fuel, 1983, 62, 1387.

9. Painter, P.C., Snyder, R.W., Pearson, D.E., and Kwong, J.; Fuel, 1980, 59, 283.

10. Chamberlain, E.A.C., Barrass, G., and Thirlaway, J.T.; Fuel, 1976, 55, 217.

11. Saini, A.K., Song, C., Schobert, H.H., and Hatcher, P.G.; ACS Fuel Chem. Prepr., 1992, 37(3), 1235.

12. Sokowiak, M.and Painter, P.; Fuel, 1992, 71, 1105.

13. Song, C., Schobert, H.H.and Hatcher, P.G.; ACS Fuel Chem. Prepr., 1992, 37(2), 638645; Energy \& Fuels, 1992, 6, 326-328. 


\section{THE STRUCTURAL ALTERATION OF LOW-RANK COAL IN LOW SEVERITY LIQUEFACTION}

\section{Introduction}

Hydrous pyrolysis experiments were preformed on low-rank coalified wood to investigate the chemical transformations that occur in huminite (vitrinite) during low-severity liquefaction. The coal chosen for the experiments was of lignite rank. It consists of a single maceral, huminite, which consists predominantly of guaiacol- and catechol-like structures. These structures are believed to be responsible for many of the retrogressive reactions during liquefaction (1). Tubing bomb reactions were varied with reaction times ranging from 30 minutes to 240 hours and temperatures ranging from $100^{\circ} \mathrm{C}$ to $350^{\circ} \mathrm{C}$. Structural characterization of the reacted residues was quantified by solid state ${ }^{13} \mathrm{C}$ NMR and flash pyrolysis/gas chromatography/mass spectrometry. The combined analytical techniques show there is a progressive loss of oxygen which corresponds with the loss of catechols and guaiacols with increasing thermal stress. Further, dehydration of these catechol structures involves the transformation to phenol, and alkyl phenol structures that make up the macromolecular structure of the altered coalified wood. Dealkylation is aiso a dominant reaction pathway, as revealed by a decrease in alkyl substitutents in the residue.

Detailed studies using NMR spectroscopic and pyrolysis GCMS techniques indicate that the natural evolution of humic coals proceeds through several fundamental stages (2-6). The transformation of huminite to vitrinite is characterized by reactions which result in complete demethylation of methoxyphenols to catechols and a concomitant reduction in catechols (and alkylated catechols), presumably through reaction to form phenols and cresols; the details of the catechol reaction are so far unknown. Low-severity hydrous pyrolysis of lignite parallels many of the natural coalification reactions.

Recently, Siskin et al. (7) have demonstrated that many of the reactions which typify coalification are facilitated, if not initiated, in the presence of water. They recognized that since coalification occurs in a water saturated system, water may play an integral role in the geochemistry of coalification. From their study of an enormous number of reactions with model compounds, several mechanisms with direct bearing on the chemical structural evolution of coal during liquefaction under hydrous conditions are clear. The demethylation reaction, for example, has been shown to be acid-catalyzed, yielding phenol as the predominant product (8). The mechanism by which the alkyl-aryl ether linkage ( $\beta-0-4)$ of the modified lignin is rearranged to the $\beta-C-5$ linkage may reasonably be expected to parallel the mechanism that Siskin et al.(7) demonstrated for their 
model compound study of the aquathermolysis of benzyl phenyl ether, in which they observed a significant yield of 2-benzylphenol; this product is a perfect analog for the rearrangement necessary to yield the $\beta-C-5$ linkage.

To date there is no mechanism proposed for the reduction of catechols and their alkylated analogs, through conversion to phenol and cresols. This reaction appears to be a principal means by which the oxygen content of coal is reduced during the transformation through the subbituminous range (2-6). Although Siskin et al. (7) have not investigated the chemistry of catechols specifically, it appears reasonable to assume that the reactions of catechols may be ionic as well as thermolytic.

\section{Experimental}

Liquefaction. A crushed sample of a coalified log described previously as the Patapsco lignite (2) was heated under hydrous conditions in a $22 \mathrm{ml}$ autoclave reactor. The reactor was charged with approximately 1 gram of coal and 7 milliliters of deionized, deoxygenated water following a procedure similar to that of Siskin et al. (7). The tubing bomb reactor was consecutively pressurized to $1000 \mathrm{psi}$ and depressurized with nitrogen three times to ensure all the oxygen was removed from the reactor. Finally it was depressurized to atmospheric pressure before heating. The bomb was inserted into a heated fluidized sand bath for different reaction periods, ranging from $30 \mathrm{~min}$. to 10 days, and at various temperatures, ranging from $100^{\circ} \mathrm{C}$ to $350^{\circ} \mathrm{C}$. After the elapsed heating times the reactor was removed and immediately quenched in water and then allowed to cool to roum temperature. The liquids and solids were collected and analyzed. Only trace amounts of gases were detected. The bombs were opened and the liquid content pipetted off. The organic matter dissolved in the water was separated by extraction with diethyl ether. The residual lignite was removed, extracted in a 50:50 mixture of benzene:methanol, dried in a vacuum oven at $45^{\circ} \mathrm{C}$ for 24 hours, and then weighed.

Analytical Procedure. The original lignite and solid residue from the reactors were analyzed by flash pyrolysis and by solid-state NMR. The flash pyrolysis technique used was that published by Hatcher et al. (4). Solid-state ${ }^{13}$ C NMR spectra were obtained by the method of cross polarization and magic angle spinning (CPMAS) using the conditions previously given (2). The spectrometer was a Chemagnetics Inc. M-100 spectrometer operating at $25.2 \mathrm{MHz}$ carbon frequency. Cycle times of $1 \mathrm{sec}$ and contact times of $1 \mathrm{msec}$ were chosen as the optimal conditions for quantitative spectroscopy. 


\section{Results_and_Discussion}

Aquathermolysis of the Patapsco lignite was conceived as a means to trace the chemical changes that occur to the dominant maceral in low-rank coals during liquefaction. Accordingly, our goal was to examine the coal before and after thermal treatment and to infer liquefaction pathways. Conversions ranged from 29 to 40 percent for the different experiments (Table 3.1). This mass loss probably reflects low-molecular-weight products formed, water, and partial solubilization of lignitic structures originally of low molecular weight. The GC/MS analysis of the water-soluble materials indicates the presence of lignin, phenols and catechols, all of which are components of the lignite prior to thermolysis. Cleavage of a few bonds on the macromolecule could conceivably produce a catechol or methoxyphenol which would be soluble in water. Another water-soluble product identified was acetic acid. This product is most likely derived from thermolysis of the side-chain carbons associated with the original lignin and coalified lignin in the sample. The content of evolved gases was not measured, because the amount of gas evolved was negligible.

The NMR data of the thermolysis residues (Figure 3.1) indicates clearly the evolutionary path during thermolysis. Comparing the NMR data for the residues with the original lignite and with gymnospermous wood coalified to higher rank (2), there appear to be several changes which describe the average chemical alteration. First, the most obvious change is the loss of aryl-O carbons having a chemical shift at $145 \mathrm{ppm}$. From previous studies (2), this peak has been assigned to aryl-O carbons in catechol-like structures in the coalified wood, based on chemical shift assignments and py,olysis data. These are thought to be originally derived from demethylation of lignin during coalification (2-6). The NMR spectrum of the aquathermolysis residue has clearly lost most of the intensity at $145 \mathrm{ppm}$, but now shows a peak at $153 \mathrm{ppm}$ which is related to aryl-O carbons in monohydric phenols. These are the primary constituents of subbituminous and high volatile bituminous coalified wood as depicted in the NMR spectra for such woods. It is obvious that the catechol-like structures of the lignitic wood have been transformed to phenol-like structures somewhat similar to those in higher rank coal. Thus, the aquathermolysis has reproduced, to some degree, the coalification reactions acting on aromatic centers.

The second most apparent change to occur during aquathermolysis is the loss of aliphatic structures. The methoxyl groups at $56 \mathrm{ppm}$ are lost from the lignitic wood as are the other alkyl-O carbons at $74 \mathrm{ppm}$, consistent with demethylation reactions and dehydroxylation of the threecarbon side-chains of lignin which occur naturally during coalification of woods. However, the loss of alkyl-C carbons (those aliphatic carbons not substituted by oxygen) is the most significant change in the aliphatic region in the aquathermolysis residue. Loss of substantial amounts of 
aliphatic carbon is not observed during coalification of wood from lignite to high volatile bituminous coal. In fact, in most coalified wood samples, loss of alkyl-C carbon occurs only at higher ranks, above that of medium volatile bituminous coal. The lack of retention of aliphatic carbon during aquathermolysis is an indication that this treatment probably does not reproduce well the low-rank coalification reactions associated with aliphatic structures. It is important to note that the alkyl-C carbons in the aquathermolysis residues become dominated by methyl carbons with increasing thermal stress.

The pyrolysis data (Figure 3.2) provide confirmation for the average changes in structure observed by NMR. The loss of catechol-like structures is documented with the significant diminution of catechols in the pyrolyzate of the aquathermolysis residue compared to that of the original lignite. This loss of catechols is the single most significant change in the pyrolysis products. The pyrolyzate of the residue mimics somewhat the pyrolysis data for subbituminous coalified wood (3), being dominated by phenol and alkylphenols. Another difference between aquathermolysis residues and the original lignitic wood is in the abundance of methoxyphenols derived from lignin-like structures. The aquathermolysis has apparently reduced the relative yields significantly, consistent with the NMR data showing loss of methoxyl carbons. Some of the methoxyphenols may have been transformed to water-soluble phenols and washed out of the residue in the aqueous phase; others may have undergone demethylation reactions, converted to catechols and then transformed to phenols.

The pyrolysis of the residue yields mostly phenol and the cresol isomers; other alkylated phenols, the $\mathrm{C}_{2}$ and $\mathrm{C}_{3}$ phenols, are not as abundant relative to phenol and cresols as the $\mathrm{C}_{2}$ and $\mathrm{C}_{3}$ phenols are in the pyrolysis of original lignite or the subbituminous log. This is probably related to the fact that alkyl substituents are not as abundant in the residue and the alkyl substituents are probably mostly methyl substituents, as was deduced from the NMR data. Thus, the lack of significant relative amounts of $\mathrm{C}_{2}$ and $\mathrm{C}_{3}$ phenols in the thermolysis residue's pyrolyzate further supports the conclusion that thermolysis does not reproduce coalification reactions with regard to the aliphatic structures in the residue. The relatively high temperatures used in this study may force proportionally more thermolytic pathways over ionic pathways. The potential for such a situation has been recognized by Siskin et al. (7).

\section{References}

1) Song, C.; Schobert, H. H.; Hatcher, P.G.; Am. Chem. Soc. Div. Fuel Chem. Prepr. 1992, 37, 638.

2) Hatcher, P. G.; Energy Fuels 1988, 2, 40 
3) Hatcher, P. G.; Lerch, H.E.; Verheyen, T. V.; Int. Jour. Coal. Geol. 1989, 13, 65.

4) Hatcher, P. G.; Lerch, H. E.; Kotra, P.K.; Verheyen, T. V.; Fuel 1988, 67, 106.

5) Hatcher, P. G.; Wilson, M.A.; Vassallo, A. M.; Int. Jour. Coal. Geol. 1989, 13, 99.

6) Hatcher, P. G.; Lerch, H. E.; Bates, A. L.; Verheyen, T. V.; Org.Geochemistry $1989,14,145$.

7) Siskin, M.; Brons, G.;Vaughn, S.N.;Katritzky, A.K.;Balasubramanian, M.; Energy \& Fuels $1990,4,488$.

8) Katritzky, A. K. and Siskir, M. Energy Fuels, 1990, 4, 475-584.

9) Katritzky, A.K.; Murugan, R.; Balasubramanian, M.; Siskin, M.; Energy Fuels :390, 4, 482.

10) Hatcher, P. G.; Org. Geochem. 1990, 16, 959.

\section{Iffects of Solvents and Catalyst Dispersion Methods in Temperature- Programmed Liquefaction}

\section{INTRODUCTION}

A characteristic of low-rank coals is that they have low carbon content and high oxygen content. The aromatic ring clusters in lo'v-rank coals are generally small, while the aliphatic crosslinks and the crosslinks containing heteroatoms, such as oxygen, are abundant [1]. This structural feature makes it easy to break coal macromolecules into fragments (radicals). Whether these radicals are stabilized by hydrogenation or by retrogressive reactions is the critical point in the liquefaction of low-rank coals. The important factors which have significant impacts on the hydrogenation or retrogressive reactions are reaction conditions (temperature, $\mathrm{H}_{2}$ pressure and time), reaction solvents and catalysts. The reaction conditions have been studied by many workers and the procedures for single-staged liquefaction (SSL), temperature-staged liquefaction (TSL) and temperature-programmed liquefaction (TPL) have been established [2-4]. The TPL was found to be superior to SSL and TSL for catalytic liquefacticn of a subbituminous coal using dispersed Mo catalyst, in terms of higher conversion and oil yield [2]. Three types of reaction solvents, hydrogen donor, non-donor, and recycle solvent, are often used, and their behavior in the liquefaction were investigated [3-6]. For the catalytic conversion, a very important aspect, besides the activity of the catalyst, is its dispersion. Several impregnation methods are often used. They are preswelling $[7,8]$, incipient wetness $[2,9,10]$ and slurrying. 
In this work, the liquefaction of DECS-1 coal was studied in comparison with DECS-9 and DECS-11 coals. Four reaction solvents were used for examining the effect of the solvent on liquefaction. The three impregnation methods mentioned above were applied to disperse the catalyst precursor, ammonium tetrathiomolybdate (ATTM), onto the coal, and their effects were studied comparatively.

\section{EXPERIMENTAL}

The coal samples were a Texas subbituminous (DECS-1), a North Dakota lignite (DECS11) and a Montana subbituminous coal (DECS-9), obtained from Penn State Coal Sample Bank. Their compositional data are summarized in Table 4.1. The coal samples were dried at $95^{\circ} \mathrm{C}$ in vacuum for $5 \mathrm{~h}, 5 \mathrm{~h}$, and $3 \mathrm{~h}$ respectively before use. The reaction solvents are tetralin (Aldrich, 99\%), decalin (Aldrich 99+\%), 1-methylnaphalene (1-MN, Aldrich, 98\%) and Wilsonville Middle Distillate (WIMD). The catalyst precursor was ammonium tetrathiomolybdate (ATTM, Aldrich, 99.97\%). All the chemicals were used without further purification.

The catalyst loading was $1 \mathrm{wt} \%$ of Mo based on the dmmf coal. A THF/ $\mathrm{H}_{2} \mathrm{O}(56: 44)$ mixture was used to make the solution of the catalyst precursor, because this binary mixture was superior to $\mathrm{H}_{2} \mathrm{O}$ in terms of higher conversion and oil yield [2]. The impregnation methods were swelling, incipient wetness and slurrying. In the swelling method, the volume of the $\mathrm{THF} / \mathrm{H}_{2} \mathrm{O}$ solution was four times of the cnal volume. The swelling was carried out at room temperature under $\mathrm{N}_{2}$ atmosphere for $24 \mathrm{~h}$ with continuous stirring. The swelling ratio was 1.85 for this coal. The swollen coal with the catalyst precursor loaded on was then dried in a vacuum oven at room temperature for $48 \mathrm{~h}$ to remove the THF, followed by drying at $40^{\circ} \mathrm{C}$ for $24 \mathrm{~h}$ and $95^{\circ} \mathrm{C}$ for $48 \mathrm{~h}$ to remove the remaining $\mathrm{THF}$ and $\mathrm{H}_{2} \mathrm{O}$. In the incipient wetness method, the precursor was dissolved in the desired volume of the $\mathrm{THF} / \mathrm{H}_{2} \mathrm{O}$ for a certain amount of the coal sample. This solution was added drop by drop while the coal was constantly stirred manually. After all the solution was added, the coal was dried in the vacuum oven at $95^{\circ} \mathrm{C}$ for $4 \mathrm{~h}$ to remove the $\mathrm{THF}$ and $\mathrm{H}_{2} \mathrm{O}$. In the slurrying method, the same amount of $\mathrm{THF} / \mathrm{H}_{2} \mathrm{O}$ mixture as that in the incipient wetness method, was used to tissolve the ATTM. The solution was then added to the coal sample to make a slurry. The slurry wa: stirred by a magnetic stirrer for 15 minutes at room temperature under $\mathrm{N}_{2}$ atmosphere, followed by drying in the vacuum oven at room temperature for $48 \mathrm{~h}, 40^{\circ} \mathrm{C}$ for $48 \mathrm{~h}$ and $95^{\circ} \mathrm{C}$ for $6 \mathrm{~h}$ to remove the THF and $\mathrm{H}_{2} \mathrm{O}$. 
Liquefaction experiments were conducted in $25 \mathrm{ml}$ tubing bombs in a preheated fluidized sandbath. For each reaction, $4 \mathrm{~g}$ of coal sample and $4 \mathrm{~g}$ of a solvent were loaded into a tubing bomb. Hydrogen was purged three times and the final pressure was $1000 \mathrm{psi}(7 \mathrm{MPa})$ at room temperature. The reactor was then plunged into the sandbath and agitated at a rate of 200 cycles per minute. For a single-staged liquefaction (SSL), the tubing bomb was rapidly heated up to $350^{\circ} \mathrm{C}$ and kept at that temperature for 30 minutes followed by rapid quench. For a temperatureprogrammed liquefaction (TPL), the tubing bomb was rapidly heated up to $200^{\circ} \mathrm{C}$, held at this temperature for 15 minutes, then slowly heated to $400^{\circ} \mathrm{C}$ at a rate of about $7^{\circ} \mathrm{C} / \mathrm{min}$, and held at that temperature for 30 minutes, finally the reactor was rapidly quenched.

After the reaction, the gases were vented, the liquids and the solids in the tubing bomb were washed into a tared ceramic thimble using hexane. Then the products were separated under a nitrogen atmosphere by Soxhlet extraction using hexane, toluene and THF sequentially. The soluble products were classified as oil, asphaltene and preasphaltene, respectively.

Most of the experiments were repeated at least once. If the difference between the two runs was larger than 4 percentage unit, the experiment was repeated again and the two closer ones were chosen to calculate the average value.

\section{RESULTS AND DISCUSSION}

In order to gain some general information about the liquefaction of the DECS-1 coal, the coal is first compared with DECS-11 and DECS- 9 under two different reactions. Table 4.2 lists the results of experiments with WIMD as the reaction solvent. In single-staged liquefaction (SSL) at $350^{\circ} \mathrm{C}$, the conversions of the three coals are all in the high twenty percent, without a significant difference. The product distributions are similar, with the exception of DECS-9. In temperatureprogrammed liquefaction (TPL) at $200^{\circ} / 400^{\circ} \mathrm{C}$, all of the three coals have dramatic increases in conversion, with the DECS- 1 increasing the most (about 10 percentage units more than the other two). However, the yields of desired light materials, such as oil and asphaltene, are identical for the three coals in TPL. The higher increase in the conversion of DECS-1 is due to the higher yield (10 percentage units) of preasphaltene.

In a summary for comparison, the liquefaction reactivity of the DECS-1 coal at mild conditions (SSL at $350^{\circ} \mathrm{C}$ ) is nearly identical with the other two coals; while changing the reaction condition to the temperature-programmed liquefaction at $200^{\circ} \mathrm{C} / 400^{\circ} \mathrm{C}$, the conversion can be 
significantly increased, though a fraction as high as one-third (22.8/67.1) of the total product is preasphaltene. Nevertheless, DECS-1 coal can still be an interesting feedstock for liquefaction, if the preasphaltene can be converted to oil, the desired product. The preasphaltene could be attributed to two types of reactions. One is the depolymerization of coal macromolecules into fragments. These fragments may dissolve in THF, but they may be so large that they do not dissolve in hexane or toluene, thus they appear as preasphaltene. The other is the recombination of small fragments. At the reaction temperature, the coal molecules may be cracked down to small fragment radicals which could be stabilized by hydrogen and produce oil or asphaltene, but due to the unavailability of hydrogen, those radicals may recombine with one another and produce preasphaltene. In the former case, the amount of preasphaltene can be reduced by further cracking the fragments, which produce the preasphaltene, into smaller ones. In the latter case, it is crucial to improve the hydrogenation of any radicals, especially those which may produce oil and asphaltene, and thus to prevent the recombination. Regardless of how the preasphaltene formed, reducing their contribution to the product slate means that we have to crack the coal macromolecular structure extensively (but not to the extreme that too much gas forms) as well as to enhance the hydrogen up-take by the system. Hence it is necessary to find the proper reaction conditions, to introduce catalysts into the reaction, and to improve the performance of the reaction solvents in liquefaction.

The effects of solvents on the liquefaction of DECS-1 coal were investigated and the results are presented in Table 4.3. In SSL at $350^{\circ} \mathrm{C}$, the reaction with tetralin has slightly higher conversion than those with other three solvents. In terms of product distribution, tetralin, WIMD and 1-MN are the same, while decalin produced lower fraction of asphaltene and preasphaltene with much higher fraction of oil plus gas. In TPL at $200^{\circ} \mathrm{C} / 400^{\circ} \mathrm{C}$, the differences in conversion caused by the reaction solvents are more apparent. The reaction with tetralin produced 10 percentage units higher conversion than the reaction with WIMD, which produced about 20 percentage units higher than those with decalin and 1-MN. In terms of product distribution under this condition, tetralin and 1-MN have very similar behavior while WIMD and decalin are on two opposite extremes. With WIMD, a large fraction of preasphaltene and smail fraction of oil were produced; while with decalin, small faction of preasphaltene and large fraction of oil were obtained. Asphaltene has same fraction of the total conversion regardless the reaction solvents.

Table 4.4.3 shows that the effects of solvents on liquefaction strongly depend on the reaction conditions. At temperatures as low as $350^{\circ} \mathrm{C}$, the coal macromolecules may not be broken down to fragments extensively, or the generation of radicals accessible to the $H$-donor solvent may not occur [6]. Therefore, the effects of solvents can not be determined because the coal-derived 
radicals, even they are generated at this temperature, are not available to the solvents. However, tetralin is a well known swelling solvent; it can diffuse into the coal particles, loosen the structure and make those radicals accessible. The other possible cause of the diminishing of the solvent effect is the low reactivity of solvents at this temperature. Hill et al. claimed that the hydrogen transfer from the solvents to the coal is not extensive [7]. While under temperature-programmed conditions $\left(200^{\circ} \mathrm{C} / 400^{\circ} \mathrm{C}\right)$, more and more free radicals are generated as the temperature rises. On the other hand, one advantage of the TPL process is to provide the chance for the solvents to diffuse into the pores in the coal particles [4] and to obtain an access to the radicals. It is observed that the order of the solvents in terms of increasing conversion is tetralin $>$ WIMD $>$ decalin $=1$ $\mathrm{MN}$ in TPL $\left(200^{\circ} \mathrm{C} / 400^{\circ} \mathrm{C}\right)$. However, as mentioned earlier, the reaction with WIMD produced very high yield of preasphaltene while the reaction with decalin produced very low preasphaltene. Previous investigation at Penn State has shown that WIMD contains abundant pyrene and hydropyrene [12] which can serve as hydrogen shuttlers [13]. During the liquefaction, the macromolecules are cracked down to radicals of different sizes. Generally, radicals of large size, or large aromatic clusters, are more stable, in other words, less active in hydrogen abstraction than the radicals of smaller sizes. With a good $\mathrm{H}$-donor, the radicals of all sizes are stabilized by hydrogen abstraction from the donor and appear as preasphaltene (for large-sized radicals), asphaltene or oil (for small-sized radicals). If the radicals of large size do not have chances to further crack down after their stabilization, the preasphaltene yield will be high. This could be one possible explanation why tetralin and WIMD produce high yield of preasphaltene. With a poor $\mathrm{H}$ donor as the reaction solvent, the radicals of large size, with low activity, may lose the competition of hydrogen abstraction to the radicals of small size. Since these radicals are not stable, they either take the pathway of recombination to form large molecules, e. g. THF-insolubles, and reduce the conversion, or they can be further cracked down to small fragment radicals which can be stabilized and produce high yields of oil and asphaltene. Therefore, donor solvents have high conversion accompanied with high preasphaltene yield while non-donor solvents have low conversion with low preasphaltene yield.

Table 4.4 shows the effects of the catalyst and the catalyst impregnation (dispersion) methods on the liquefaction. Temperature-programmed liquefaction was first conducted with WIMD as reaction solvent. It was found that there was a significant increase in the total conversion, comparing the average of all catalytic runs with the thermal run, and the product slate was drastically shifted to enhance the gas + oil yield at the expense of the asphaltene and preasphaltene, which can be seen in Table 4.4. As for the effects of impregnation methods in TPL, total conversions of the reactions using the s.welling and the incipient wetness methods are very close and that using the slurrying method is slightly lower. These data show that at proper 
reaction conditions such as TPL, the impregnation method does not play a significant role in the liquefaction.

Comparing Table 4.2 and Table 4.3, it is found that the reaction conditions have very significant impacts on the conversion. Any small differences in catalyst dispersion caused by different impregnation methods will be diminished by the strong effects of reaction conditions. Therefore, it is necessary to carry out liquefaction experiments at milder conditions in order to study the effects of the impregnation methods.

Single-staged liquefaction at $350^{\circ} \mathrm{C}$ was carried out, again, with WIMD as reaction solvent, and the results are listed in Ta'sle 4.4. Comparing the average of all the catalytic runs with the thermal run, it is observed that the catalyst is active under this condition, though its impact on conversion [(36.8-29.7)/29.7 $=24 \%]$ is not as large as that in TPL [(91.0-67.1)=36\%]. This is an evidence that the catalyst is more active in $\operatorname{TPL}\left(200^{\circ} \mathrm{C} / 400^{\circ} \mathrm{C}\right)$ than in SSL $\left(350^{\circ} \mathrm{C}\right)$. The catalytic SSL managed to reduce the preasphaltene, relative to non-cataiytic reaction, but the main effect is to enhance asphaltenes at the expense of preasphaltene, because there is no increase in the proportion of gas + oil. In other words, at less severe conditions, the use of the catalyst promotes the conversion from preasphaltene to asphaltene, but contributes little to their conversion to oil. As for the effect of impregnation methods, the swelling method seems to be better than the other two in terms of gaining higher conversion under this mild condition. However in terms of the product distribution, it does not show any significant advantage.

With the possibility that solvent effect could also diminish the differences caused by different impregnation methods, liquefaction experiments were also conducted with 1 mehtylnaphthalene 2 s the reaction solvent under single-staged conditions $\left(350^{\circ} \mathrm{C}\right)$, and the results are shown in Table 4.4. The effect of the catalyst is very significant in this case [(50.5$31.4) / 31.4=61 \%$ ] relative to that when WIMD was used as solvent $(24 \%)$; the values of the conversions are also higher. However, as shown in Table 4.4, the product distributions of the catalytic and thermal runs are identical, which are not quite the same as that when WIMD is used as the solvent. In term of the effects of impregnation methods, the swelling method again shows its advantage in providing higher conversion while no advantage in product distribution.

\section{CONCLUSION}

At mild reaction conditions, e.g. single-staged at $350^{\circ} \mathrm{C}$, the DECS-1 coal behaves very similar to DECS-9 and DECS-11 coals. At higher temperature and better designed reaction procedures, e.g. temperature-programmed at $200^{\circ} \mathrm{C} / 400^{\circ} \mathrm{C}$, the coal is very interesting in the way that it has higher conversion than the other two, which is due to the higher yield of the 
preasphaltene. The study of the reaction solvents shows that at low temperature and single-staged condition, they do not make much difference, while at higher temperature in TPL, the order of them in terms of producing high conversion is tetralin $>$ WIMD $>$ decalin $=1-\mathrm{MN}$. However, in terms of oil or preasphaltene yield, the order is not the same. Some possible explanations are proposed. The applied catalyst (ATTM) is very effective in achieving high conversion, especially in shifting the product distribution to high fractions of the oil. The effect of the catalyst impregnation methods on the catalyst activity was investigated and it was found that under an optimum reaction condition, such as temperature-programmed at $200^{\circ} \mathrm{C} / 400^{\circ} \mathrm{C}$, this effect is negligible relative to the thermal effect and catalytic effect. Under milder conditions, e.g. $350^{\circ} \mathrm{C}$, the swelling method is superior to the others in terms of conversion. However, regarding the fraction of product distribution, the three methods can be considered identical.

\section{REFERENCE}

1. Schobert, H. H. Resources, Conservation and Recycling, 1990, 3, 111-123

2. Huang, L., Song, C., Schobert, H. H., Am. Chem. Soc. Div. Fuel Chem. Prepr., 1992, 37(1), 223-227

3. Song, C., Schobert, H. H., Energy \& Fuel, 1992, 6, 326-328

4. Song, C., Schobert, H. H., Am. Chem. Soc. Div. Fuel Chem. Prepr., 1992, 37(2),976-983

5. Vlieger, J. J., Kieboom, A. P., Bekkum, H. V., Fuel, 1984, 63, 334-340

6. Schulten, H. R., Marzec, A., Fuel Proc. Tech., 1987,15, 307-318

7. Hill, G. R., Hairiri, H., Reed, R. I., and Anderson, L. L., Am. Chem. Soc., Advances in Chem. Ser. 1966, 55, 427-447

8. Joseph, J. T., Fuel, 1991, 70, 459-464

9. Joseph, J. T., Fuel, 1991, 70, 139-144

10. Utz, B. R., Cugini, A. V., and Frommel, E. A., Am. Chem. Soc. Div. Fuel Chem. Prepr., 1989, 34(4), 1423

11. Derbyshire, F. and Hager, T., Am. Chem. Soc. Div. Fuel Chem. Prepr., 1992, 37, 312-319

12. Lai, W., Song, C., Schobert, H. H., Am. Chem. Soc. Div. Fuel Chem. Prepr., 1992, 37(4), 1671-1680

13. Derbyshire, F. T., Varghess, P., Whitehurst, D. D., Fuel, 1982, 61, 859-864 
Table 1.1. Products distributions (wt.\% dmmf coal) for the thermal liquefactions at $350{ }^{\circ} \mathrm{C}$ of raw and coal dried under different conditions.

\begin{tabular}{|c|c|c|c|c|c|}
\hline Drying Conditions. & Gas* & Oil & Asphal. & Preasp. & $\begin{array}{l}\text { Total } \\
\text { Conv. }\end{array}$ \\
\hline \multicolumn{6}{|l|}{ Solvent-free } \\
\hline Raw-undried & $7.7(9.5)$ & 5.4 & 2.8 & 9.1 & 25.0 \\
\hline Air-dried, $2 \mathrm{~h}, 100^{\circ} \mathrm{C}$ & $5.0(6.3)$ & 3.3 & 0.7 & 5.8 & 14.8 \\
\hline Air-dried, $20 \mathrm{~h}, 100^{\circ} \mathrm{C}$ & $5.7(7.3)$ & 6.0 & 0.6 & 3.2 & 15.5 \\
\hline Air-dried, $100 \mathrm{~h}, 100^{\circ} \mathrm{C}$ & $8.5(12.0)$ & 1.2 & 0.7 & 3.3 & 12.7 \\
\hline Air-dried, $20 \mathrm{~h}, 150^{\circ} \mathrm{C}$ & $9.8(13.2)$ & 0.6 & 0.2 & 0.4 & 10.9 \\
\hline Vac.-dried, $2 \mathrm{~h}, 100^{\circ} \mathrm{C}$ & $3.3(5.9)$ & 2.1 & 2.6 & 4.5 & 12.5 \\
\hline \multicolumn{6}{|l|}{ Tetralin } \\
\hline Raw-undried & $5.8(7.7)$ & 15.8 & 9.3 & 12.4 & 43.3 \\
\hline Air-dried, $2 \mathrm{~h}, 100^{\circ} \mathrm{C}$ & $5.4(6.3)$ & 11.7 & 7.4 & 10.6 & 35.1 \\
\hline Air-dried, $20 \mathrm{~h}, 100^{\circ} \mathrm{C}$ & $5.98 .7)$ & 11.1 & 6.5 & 8.9 & 32.4 \\
\hline Air-dried, $100 \mathrm{~h}, 100^{\circ} \mathrm{C}$ & $8.7(11.6)$ & 6.1 & 6.3 & 9.7 & 30.8 \\
\hline Air-dried, $20 \mathrm{~h}, 150^{\circ} \mathrm{C}$ & $11.8(16.6)$ & 2.1 & 2.8 & 3.2 & 19.9 \\
\hline Vac.-dried, $2 \mathrm{~h}, 100^{\circ} \mathrm{C}$ & $4.2(5.4)$ & 4.1 & 7.6 & 10.0 & 25.9 \\
\hline \multicolumn{6}{|l|}{ 1-Methylnaphthalene } \\
\hline Raw-undried & $5.9(8.4)$ & 15.9 & 6.6 & 11.4 & 39.9 \\
\hline Air-dried, $2 \mathrm{~h}, 100^{\circ} \mathrm{C}$ & $5.1(7.6)$ & 4.2 & 4.0 & 9.4 & 22.7 \\
\hline Air-dried, $20 \mathrm{~h}, 100^{\circ} \mathrm{C}$ & $6.2(7.5)$ & 8.0 & 5.6 & 4.7 & 24.5 \\
\hline Air-dried, $100 \mathrm{~h}, 100^{\circ} \mathrm{C}$ & $9.0(12.7)$ & 1.7 & 4.1 & 6.3 & 21.1 \\
\hline Air-dried, $20 \mathrm{~h}, 150^{\circ} \mathrm{C}$ & $11.4(16.5)$ & 1.8 & 2.2 & 2.5 & 18.0 \\
\hline Vac.-dried, $2 \mathrm{~h}, 100^{\circ} \mathrm{C}$ & $4.0(5.7)$ & 1.1 & 5.8 & 7.4 & 18.3 \\
\hline
\end{tabular}

The figures in parenthesis give the total gas yields calculated from $\mathrm{GC}$ analysis. 
Table 1.2. Products distributions (wt. $\%$ dmmf coal) for the catalytic liquefactions at $350{ }^{\circ} \mathrm{C}$ of coal dried under different conditions.

\begin{tabular}{|c|c|c|c|c|c|}
\hline Drying Conditions. & Gas* & Oil & Asphal. & Preasp. & $\begin{array}{l}\text { Total } \\
\text { Conv. }\end{array}$ \\
\hline \multicolumn{6}{|l|}{ Solvent-free } \\
\hline Raw-undried & $2.2(4.3)$ & 16.9 & 9.2 & 14.9 & 43.3 \\
\hline Air-dried, $2 \mathrm{~h}, 100^{\circ} \mathrm{C}$ & $3.3(6.2)$ & 12.6 & 3.2 & 10.1 & 29.2 \\
\hline Air-dried, $20 \mathrm{~h}, 100^{\circ} \mathrm{C}$ & $4.8(6.8)$ & 14.6 & 3.1 & 8.7 & 31.2 \\
\hline Air-dried, $100 \mathrm{~h}, 100^{\circ} \mathrm{C}$ & $7.6(9.3)$ & 13.3 & 2.4 & 5.1 & 28.4 \\
\hline Air-dried, $20 \mathrm{~h}, 150^{\circ} \mathrm{C}$ & $11.2(11.2)$ & 5.1 & 0.5 & 1.7 & 18.5 \\
\hline Vac.-dried,2h, $100^{\circ} \mathrm{C}$ & $3.0(2.9)$ & 10.0 & 5.4 & 11.4 & 29.8 \\
\hline \multicolumn{6}{|l|}{$\begin{array}{ll}\text { Solvent } & \text { Tetralin }\end{array}$} \\
\hline Raw-undried & $2.8(4.9)$ & 16.0 & 11.5 & 11.9 & 42.2 \\
\hline Air-dried, $2 \mathrm{~h}, 100^{\circ} \mathrm{C}$ & $3.9(5.5)$ & 15.7 & 11.1 & 14.9 & 45.6 \\
\hline Air-dried, $20 \mathrm{~h}, 100^{\circ} \mathrm{Z}$ & $5.6(7.4)$ & 18.6 & 8.6 & 10.7 & 43.5 \\
\hline Air-dried, $100 \mathrm{~h}, 100^{\circ} \mathrm{C}$ & $6.7(9.7)$ & 16.5 & 10.8 & 11.0 & 45.0 \\
\hline Air-dried, $20 \mathrm{~h}, 150^{\circ} \mathrm{C}$ & $11.8(13.2)$ & 9.6 & 2.3 & 5.7 & 29.4 \\
\hline Vac.-dried, $2 \mathrm{~h}, 100^{\circ} \mathrm{C}$ & $3.0(2.9)$ & 10.2 & 12.9 & 10.6 & 36.4 \\
\hline \multicolumn{6}{|l|}{ Solvent $\quad 1-\mathrm{MN}$} \\
\hline Raw-undried & $3.2(5.0)$ & 10.4 & 10.4 & 11.9 & 35.9 \\
\hline Air-dried, $2 \mathrm{~h}, 100^{\circ} \mathrm{C}$ & $3.0(5.8)$ & 10.3 & 8.1 & 16.0 & 37.4 \\
\hline Air-dried, $20 \mathrm{~h}, 100^{\circ} \mathrm{C}$ & $6.4(10.0)$ & 14.1 & 8.7 & 10.5 & 39.7 \\
\hline Air-dried, $100 \mathrm{~h}, 100^{\circ} \mathrm{C}$ & $5.2(10.3)$ & 14.4 & 8.7 & 11.1 & 39.4 \\
\hline Air-dried, $20 \mathrm{~h}, 150^{\circ} \mathrm{C}$ & $12.1(13.0)$ & 5.3 & 2.8 & 4.3 & 24.5 \\
\hline Vac.-dried, $2 \mathrm{~h}, 100^{\circ} \mathrm{C}$ & $2.6(3.7)$ & 6.1 & 10.1 & 12.3 & 31.1 \\
\hline
\end{tabular}

The figures in parenthesis give the gas yields calculated from $\mathrm{GC}$ analysis. 


\begin{tabular}{|c|c|c|c|c|}
\hline \multirow{4}{*}{ 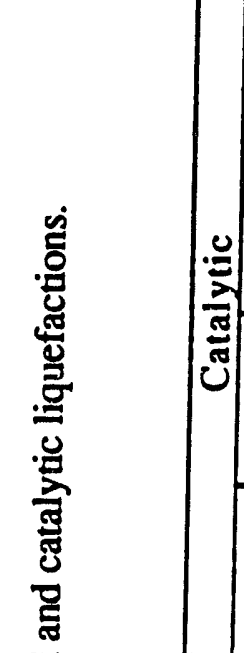 } & i⿱艹 & 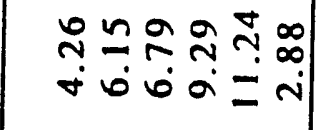 & 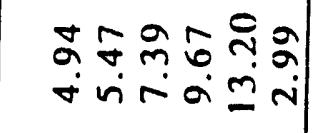 & 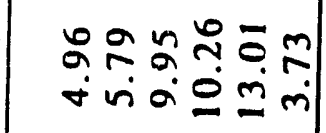 \\
\hline & $\frac{1}{0}$ & 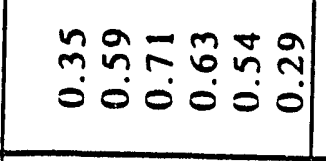 & 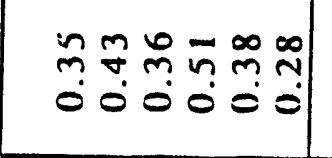 & 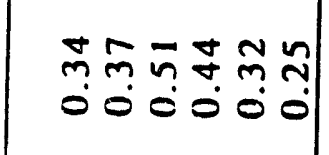 \\
\hline & 8 & 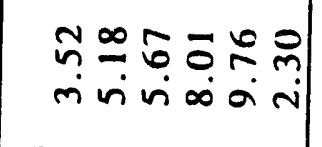 & 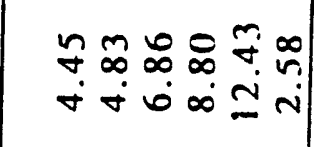 & 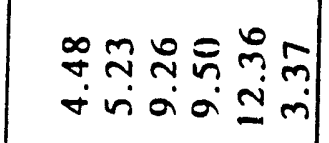 \\
\hline & 18 & 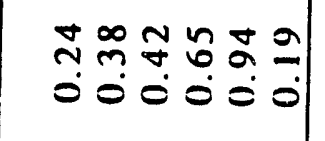 & 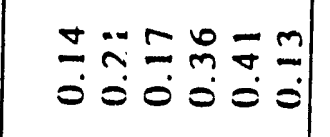 & 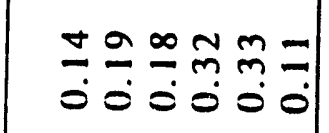 \\
\hline 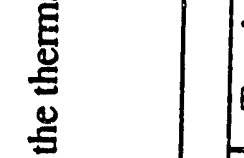 & F & 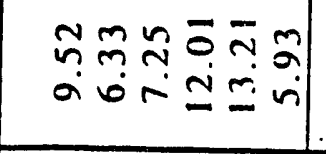 & 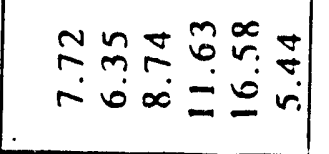 & 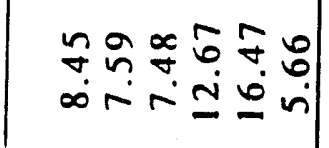 \\
\hline हु) & $y^{j}$ & 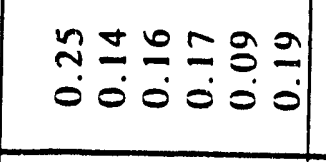 & 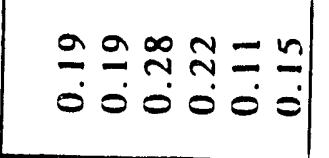 & 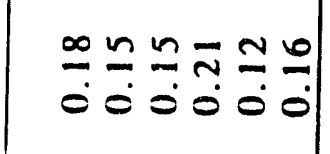 \\
\hline$F$ & 8 & 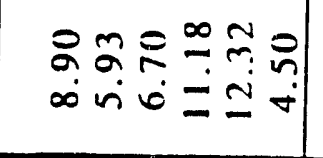 & 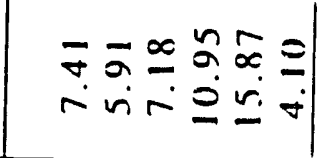 & 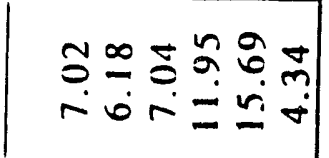 \\
\hline & 8 & 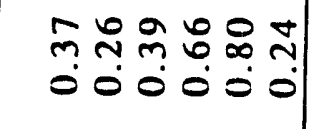 & 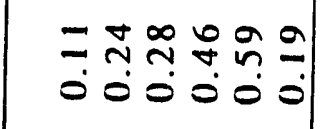 & 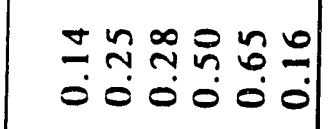 \\
\hline 我 & 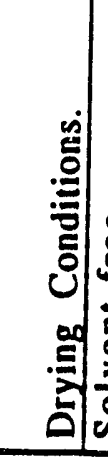 & 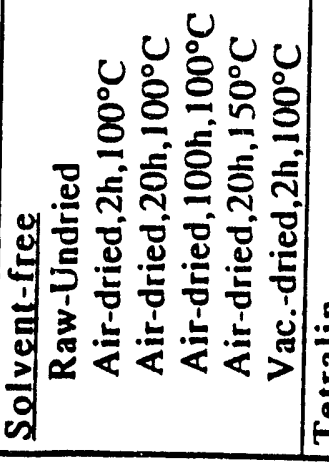 & 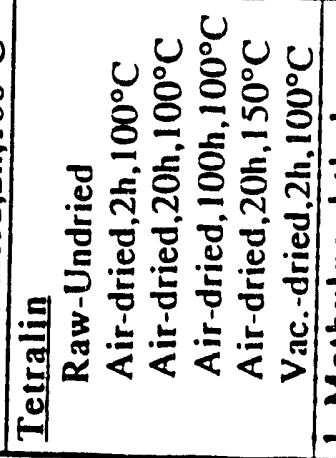 & 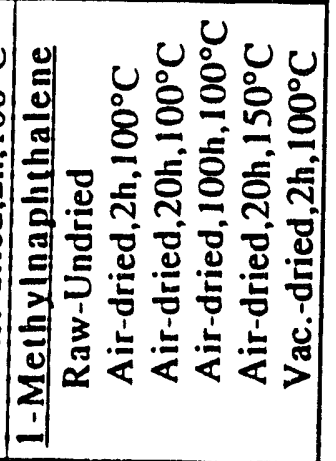 \\
\hline
\end{tabular}


Table 2.1 Ratios of the amounts of the phenolic compounds to the alkylbenzenes.

\begin{tabular}{|c|c|c|c|}
\hline \multirow[t]{2}{*}{ Drying Conditions } & \multirow[t]{2}{*}{ Unreacted Coal } & \multicolumn{2}{|c|}{ Residues } \\
\hline & & Thermal & Catalytic \\
\hline $\begin{array}{l}\text { Solvent-Eree } \\
\text { Raw } \\
\text { Air-dried,2h, } 100 \\
\text { Air-dried, } 20 \mathrm{~h}, 100^{\circ} \mathrm{C} \\
\text { Air-dried, } 100 \mathrm{~h}, 100^{\circ} \mathrm{C} \\
\text { Air-dried, } 20 \mathrm{~h}, 150^{\circ} \mathrm{C} \\
\text { Vacuum-dried } \\
\end{array}$ & $\begin{array}{l}3.8 \\
3.5 \\
2.5 \\
2.3 \\
1.1 \\
3.6\end{array}$ & $\begin{array}{l}1.9 \\
2.0 \\
2.4 \\
2.0 \\
1.2 \\
2.2\end{array}$ & $\begin{array}{l}2.8 \\
2.8 \\
2.6 \\
2.2 \\
1.6 \\
2.4\end{array}$ \\
\hline $\begin{array}{l}\text { Tetralin } \\
\text { Raw } \\
\text { Air-dried,2h,100 } \\
\text { Air-dried,20h,100 } \\
\text { Air-dried, } 100 \mathrm{~h}, 100^{\circ} \mathrm{C} \\
\text { Air-dried,20h, } 150^{\circ} \mathrm{C} \\
\text { Vacuum-dried } \\
\end{array}$ & & $\begin{array}{l}2.5 \\
3.3 \\
2.8 \\
2.2 \\
1.4 \\
3.1 \\
\end{array}$ & $\begin{array}{l}2.9 \\
3.7 \\
3.3 \\
2.6 \\
1.5 \\
3.1 \\
\end{array}$ \\
\hline $\begin{array}{l}\text { 1-Methylnaphthalene } \\
\text { Raw } \\
\text { Air-dried, } 2 \mathrm{~h}, 100 \\
\text { Air-dried,20h, } 100^{\circ} \mathrm{C} \\
\text { Air-dried, } 100 \mathrm{~h}, 100^{\circ} \mathrm{C} \\
\text { Air-dried,20h, } 150^{\circ} \mathrm{C} \\
\text { Vacuum-dried }\end{array}$ & & $\begin{array}{l}2.2 \\
2.4 \\
2.4 \\
1.5 \\
1.3 \\
1.8\end{array}$ & $\begin{array}{l}2.0 \\
2.7 \\
2.8 \\
2.3 \\
1.1 \\
2.3\end{array}$ \\
\hline
\end{tabular}

Table 3.1 Conversion data for hydrous pyrolysis experiments.

\begin{tabular}{cccc}
\hline$\#$ & time & $\begin{array}{c}\text { temperatu } \\
\text { re }\end{array}$ & $\begin{array}{c}\text { conversio } \\
\text { n, \% }\end{array}$ \\
\hline 1 & $240 \mathrm{hrs}$ & $100^{\circ} \mathrm{C}$ & 29.3 \\
2 & $.5 \mathrm{hrs}$ & $300^{\circ} \mathrm{C}$ & 29.8 \\
3 & $2 \mathrm{hrs}$ & $300^{\circ} \mathrm{C}$ & 30.6 \\
4 & $3 \mathrm{hrs}$ & $350^{\circ} \mathrm{C}$ & 39.7 \\
\hline
\end{tabular}


Table 4.1.Proximate and ultimate analysis of the coals

\begin{tabular}{|c|c|c|c|}
\hline & DECS-1 & DECS-11 & DECS-9 \\
\hline $\begin{array}{l}\text { Proximate Ana } \\
\text { \% moisture } \\
\% \text { ash } \\
\% \text { volatile } \\
\% \text { fixed carbon }\end{array}$ & $\begin{array}{l}\text { (As Rec } \\
30.0 \\
11.1 \\
33.2 \\
25.8\end{array}$ & $\begin{array}{l}33.4 \\
6.4 \\
37.4 \\
22.9\end{array}$ & $\begin{array}{l}24.7 \\
4.8 \\
33.5 \\
37.1\end{array}$ \\
\hline \multicolumn{4}{|c|}{ Ultimate Analysis (dmmn } \\
\hline $\begin{array}{l}\text { \% carbon } \\
\% \text { hydrogen } \\
\% \text { nitrogen } \\
\% \text { organic sulfur } \\
\% \text { oxygen (diff) }\end{array}$ & $\begin{array}{l}76.1 \\
5.5 \\
1.5 \\
1.1 \\
15.8\end{array}$ & $\begin{array}{l}74.2 \\
4.4 \\
1.0 \\
0.44 \\
20.0\end{array}$ & $\begin{array}{l}76.1 \\
5.1 \\
0.9 \\
0.3 \\
17.5\end{array}$ \\
\hline
\end{tabular}

Table 4.2 Comparison of DECS-1 with DECS-9 and DECS-11 in TPL and SSL with WIMD' as solvent

\begin{tabular}{|c|c|c|c|c|}
\hline Coal Samples & Tot. Conv. & Oil + Gas & Asph. & Preasph. \\
\hline \multicolumn{5}{|l|}{ SSL $\left(350^{\circ} \mathrm{C}\right)$} \\
\hline $\begin{array}{l}\text { DECS-1 } \\
\text { DECS-11 } \\
\text { DECS-9 }\end{array}$ & $\begin{array}{l}29.9 \\
25.3 \\
28.0\end{array}$ & $\begin{array}{l}16.7 \\
17.5 \\
10.1\end{array}$ & $\begin{array}{l}7.2 \\
4.6 \\
10.2\end{array}$ & $\begin{array}{l}6.0 \\
3.3 \\
7.8\end{array}$ \\
\hline \multicolumn{5}{|c|}{$\mathrm{TPL}\left(200^{\circ} \mathrm{C} / 400^{\circ} \mathrm{C}\right)$} \\
\hline $\begin{array}{l}\text { DECS-1 } \\
\text { DECS-11 } \\
\text { DECS-9 }\end{array}$ & $\begin{array}{l}67.1 \\
57.1 \\
55.9\end{array}$ & $\begin{array}{l}28.5 \\
31.9 \\
26.9\end{array}$ & $\begin{array}{l}15.8 \\
15.2 \\
17.6\end{array}$ & $\begin{array}{l}22.8 \\
10.0 \\
11.4\end{array}$ \\
\hline
\end{tabular}




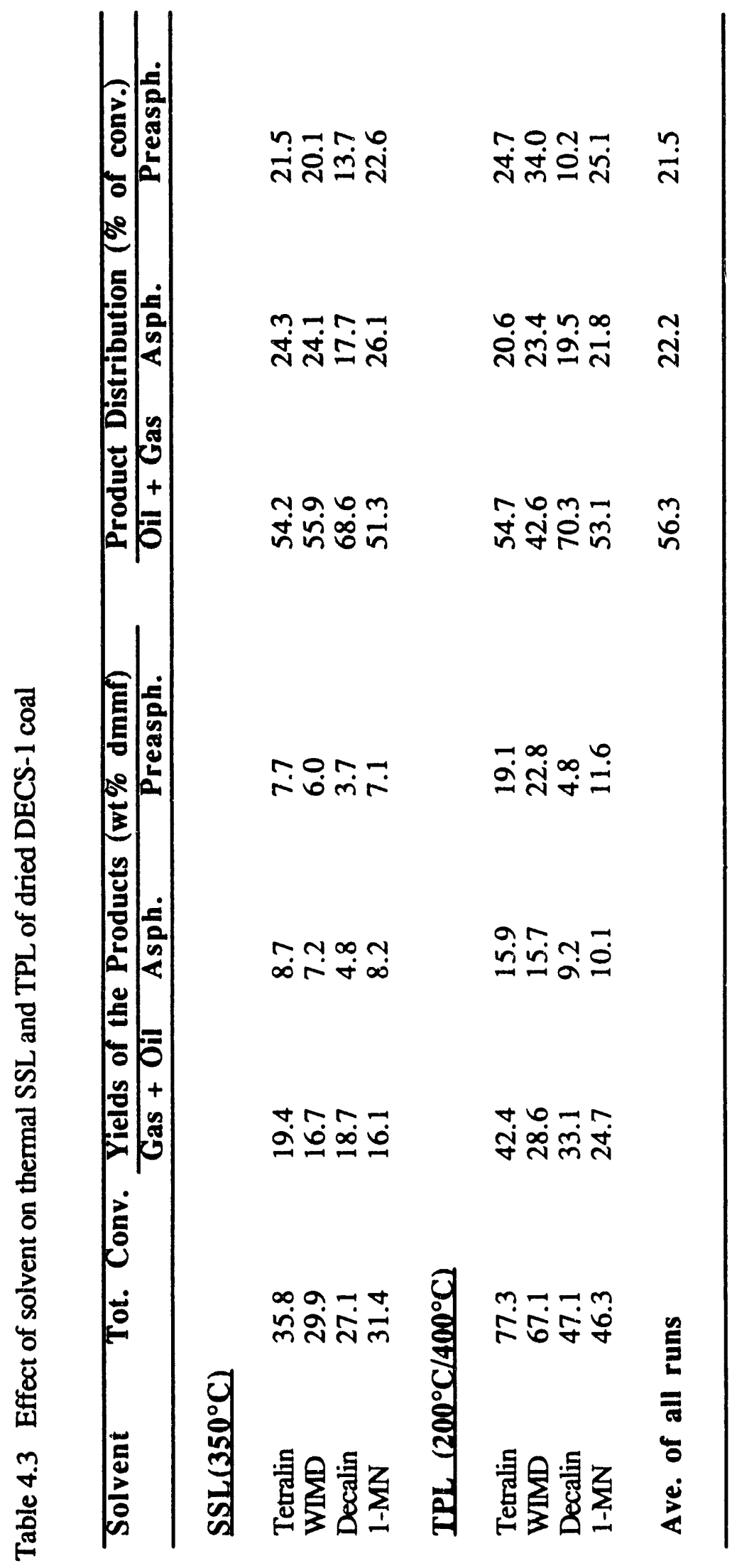




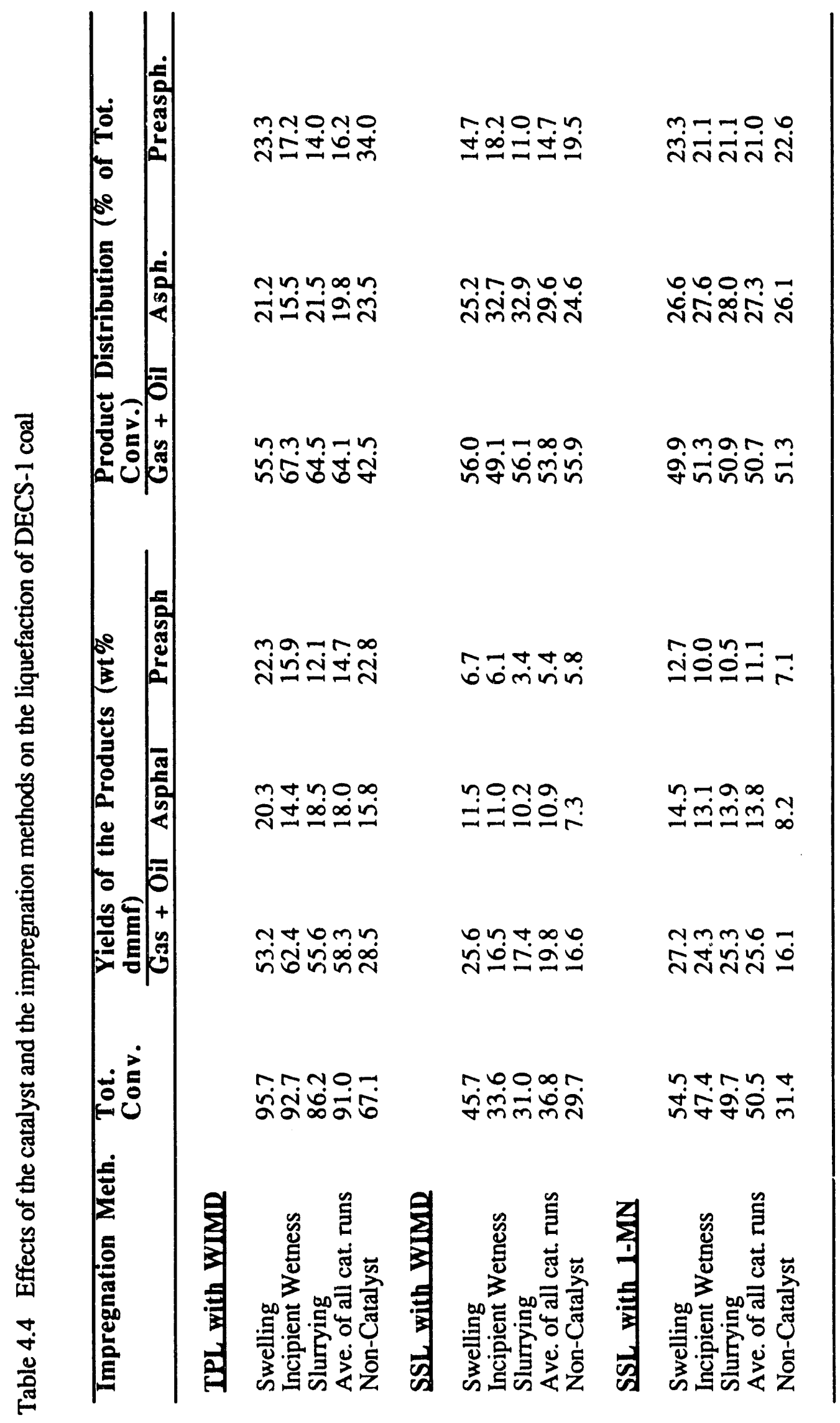



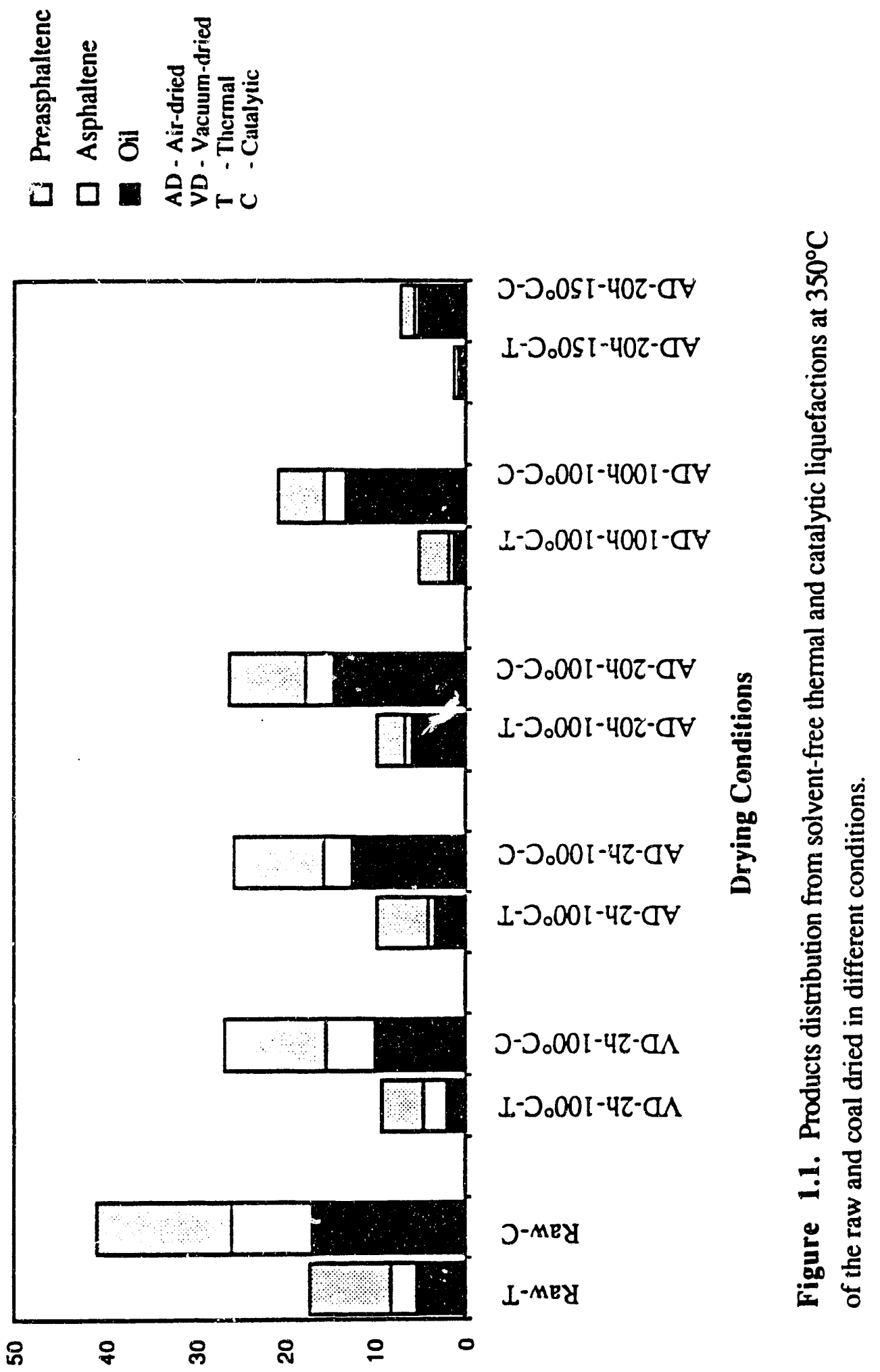

joos fuup \% iM 

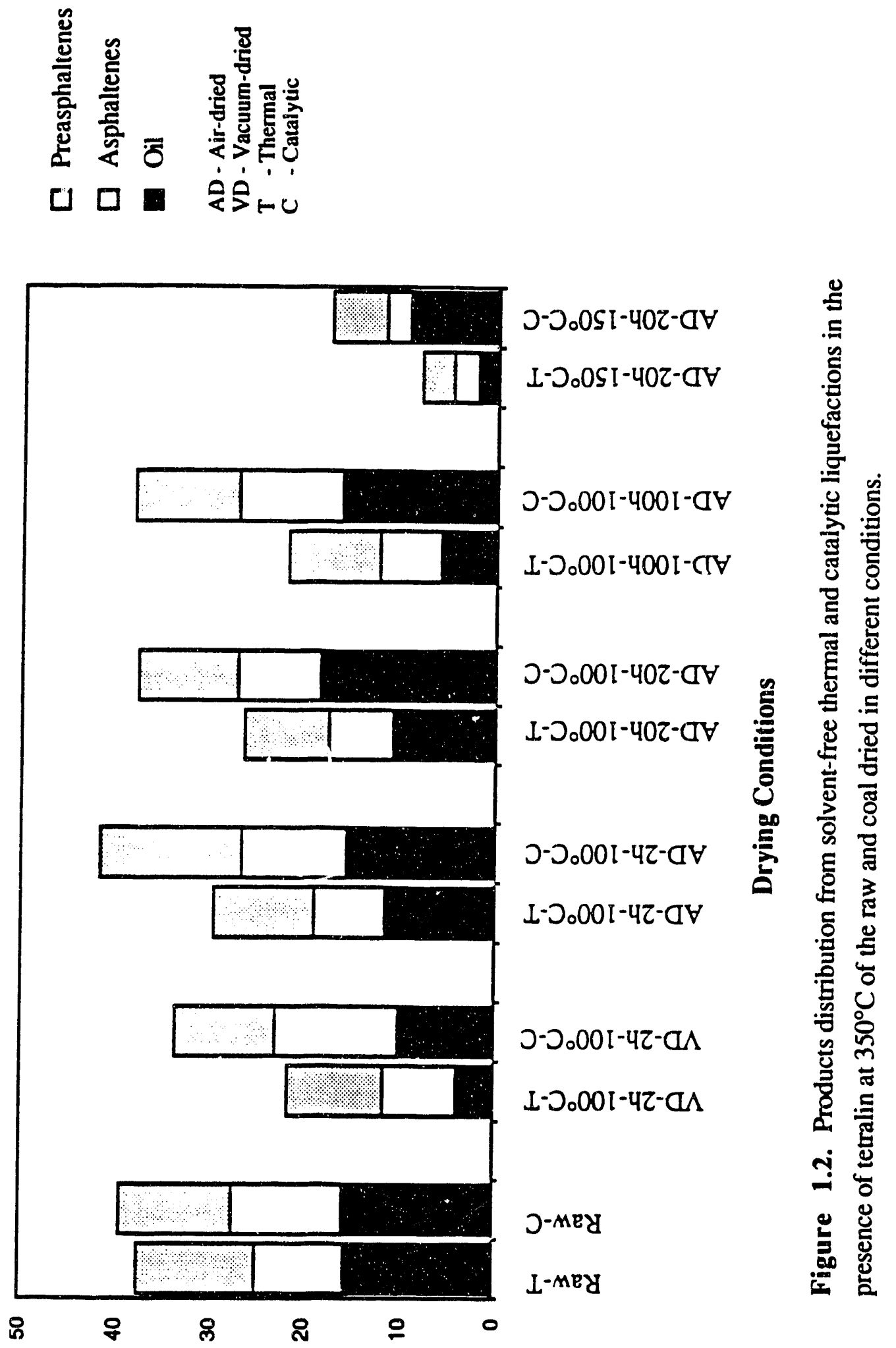

1800 fwwp \% iM 

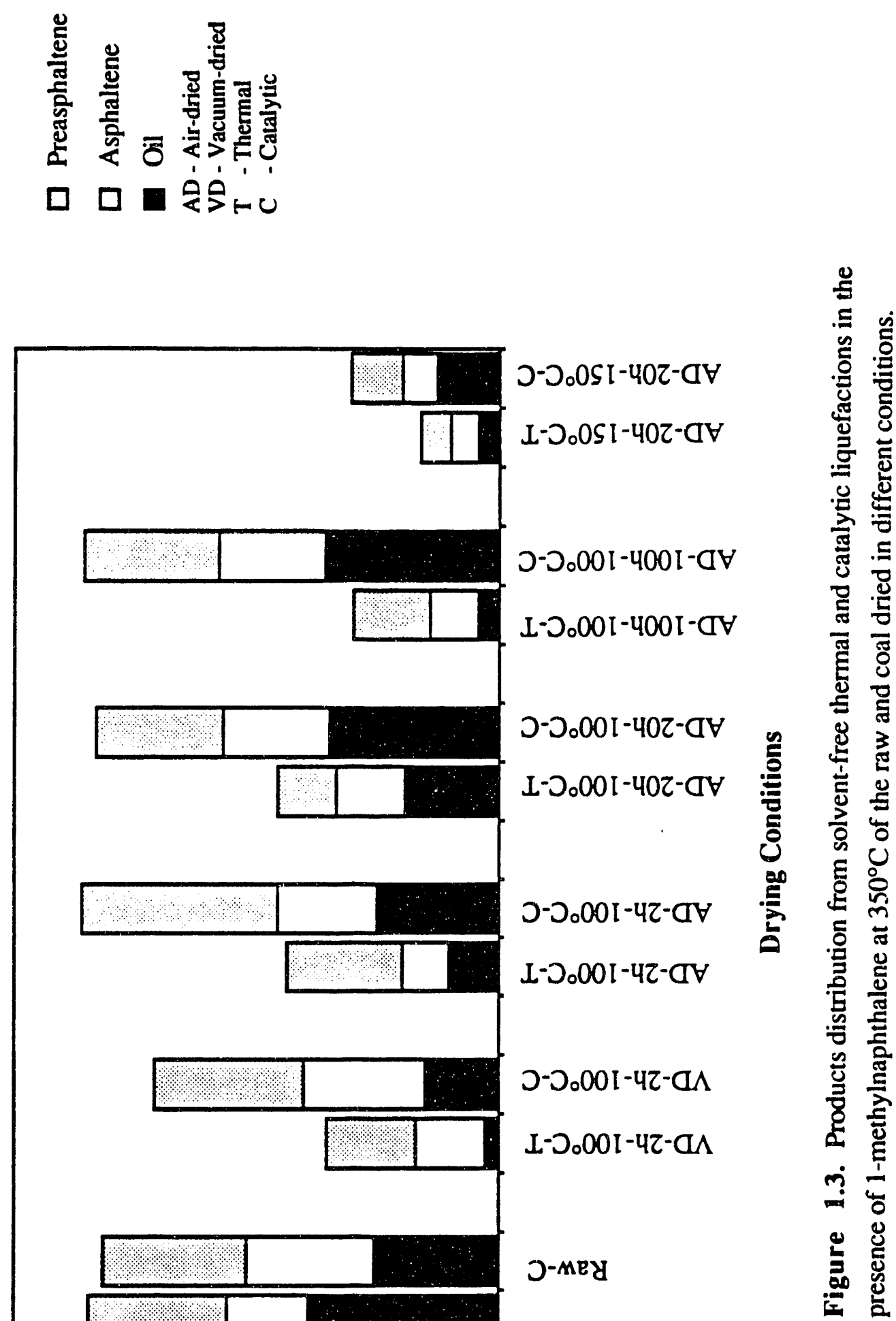

loos funw \% IM 


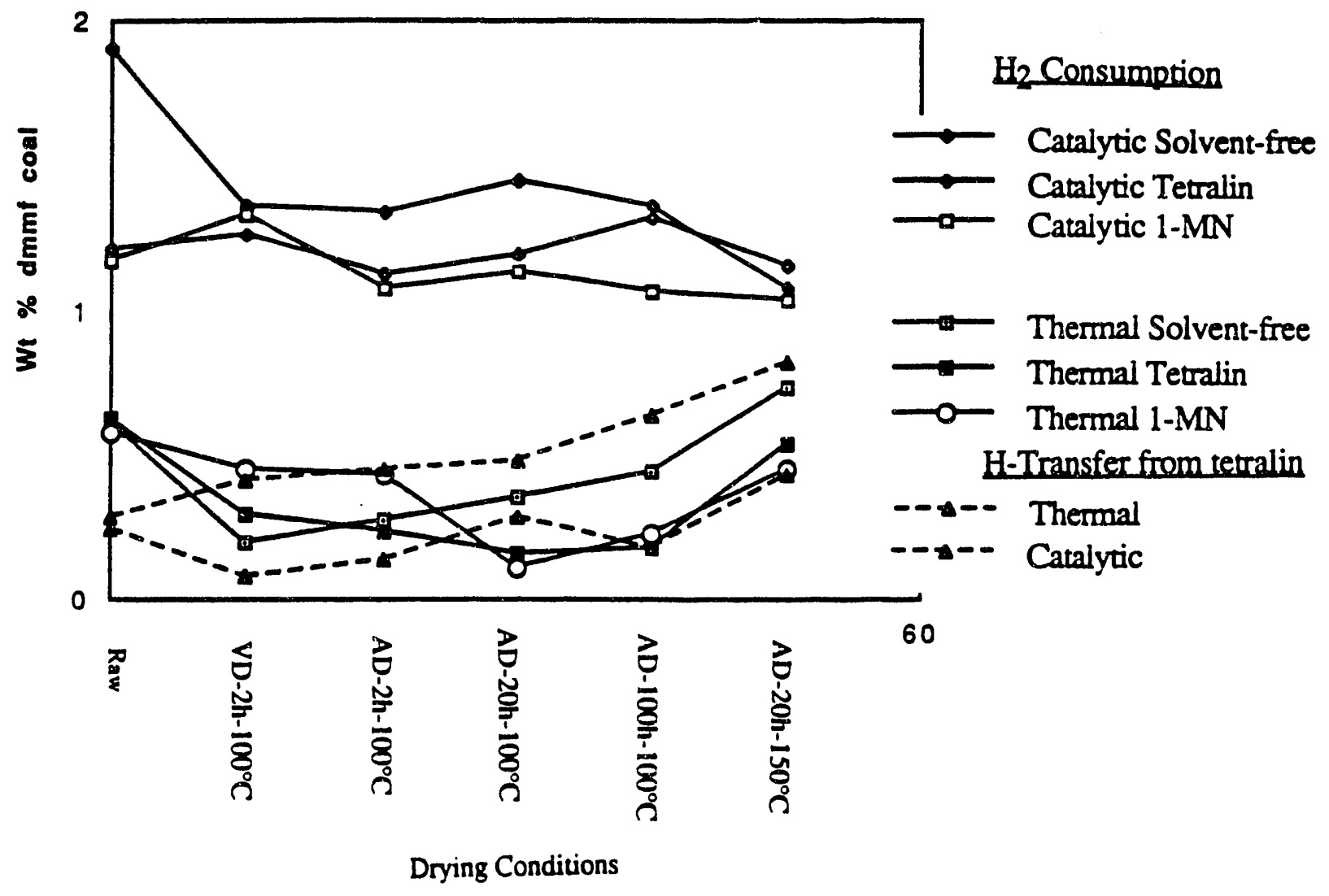

Figure 1.4. Hydrogen consumption profiles during thermal and catalytic liquefactions from $\mathrm{H}_{2}$ and tetraln. 


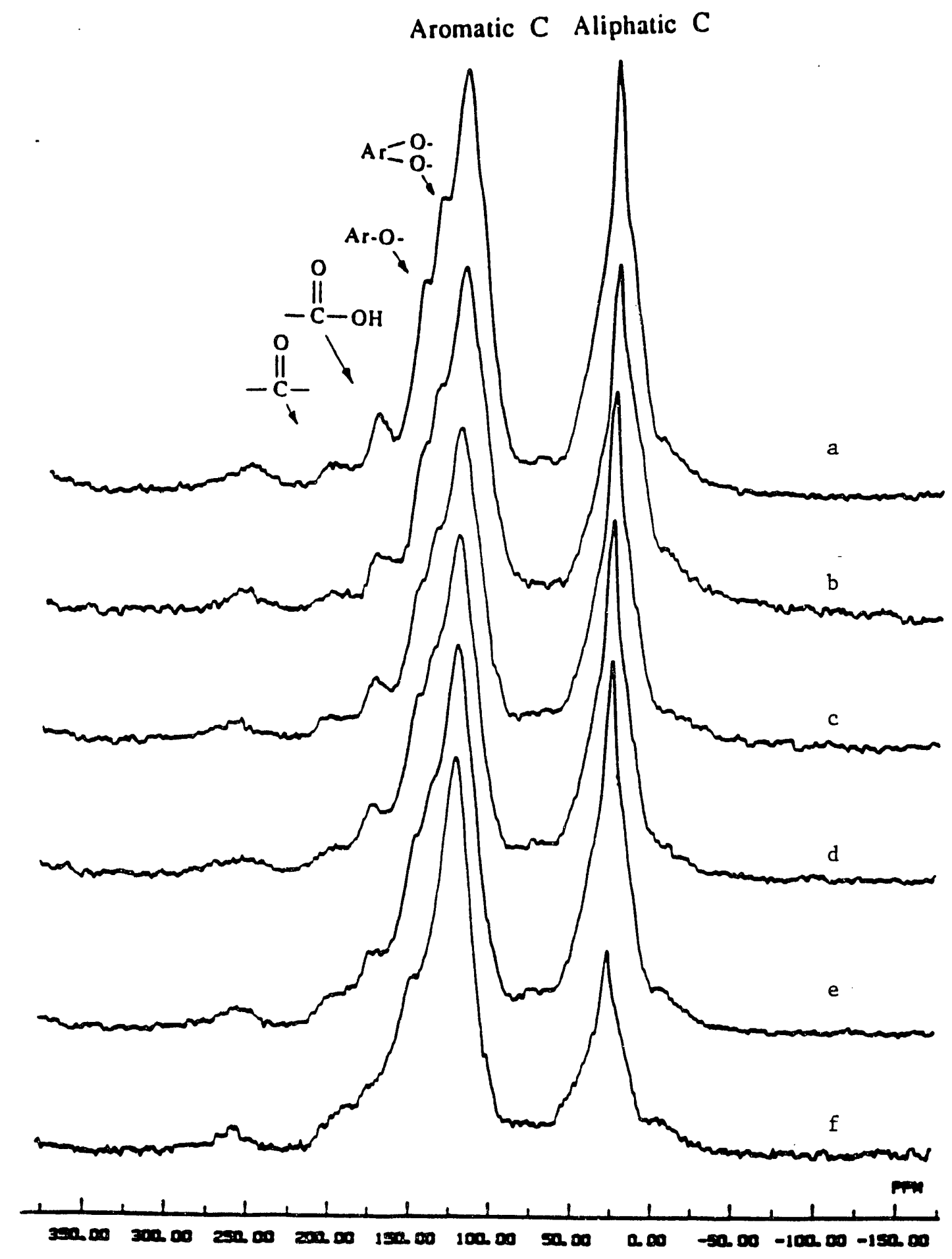

Figure 2.1. CPMAS $13 \mathrm{C}$ NMR spectra of the coal a) raw, b) vacuum-dried at $100^{\circ} \mathrm{C}$, dried in air at $100^{\circ} \mathrm{C}$ for c) $2 \mathrm{~h}$, d) $20 \mathrm{~h}$, e) $100 \mathrm{~h}$, and f) dried at $150^{\circ} \mathrm{C}$ for $20 \mathrm{~h}$. 


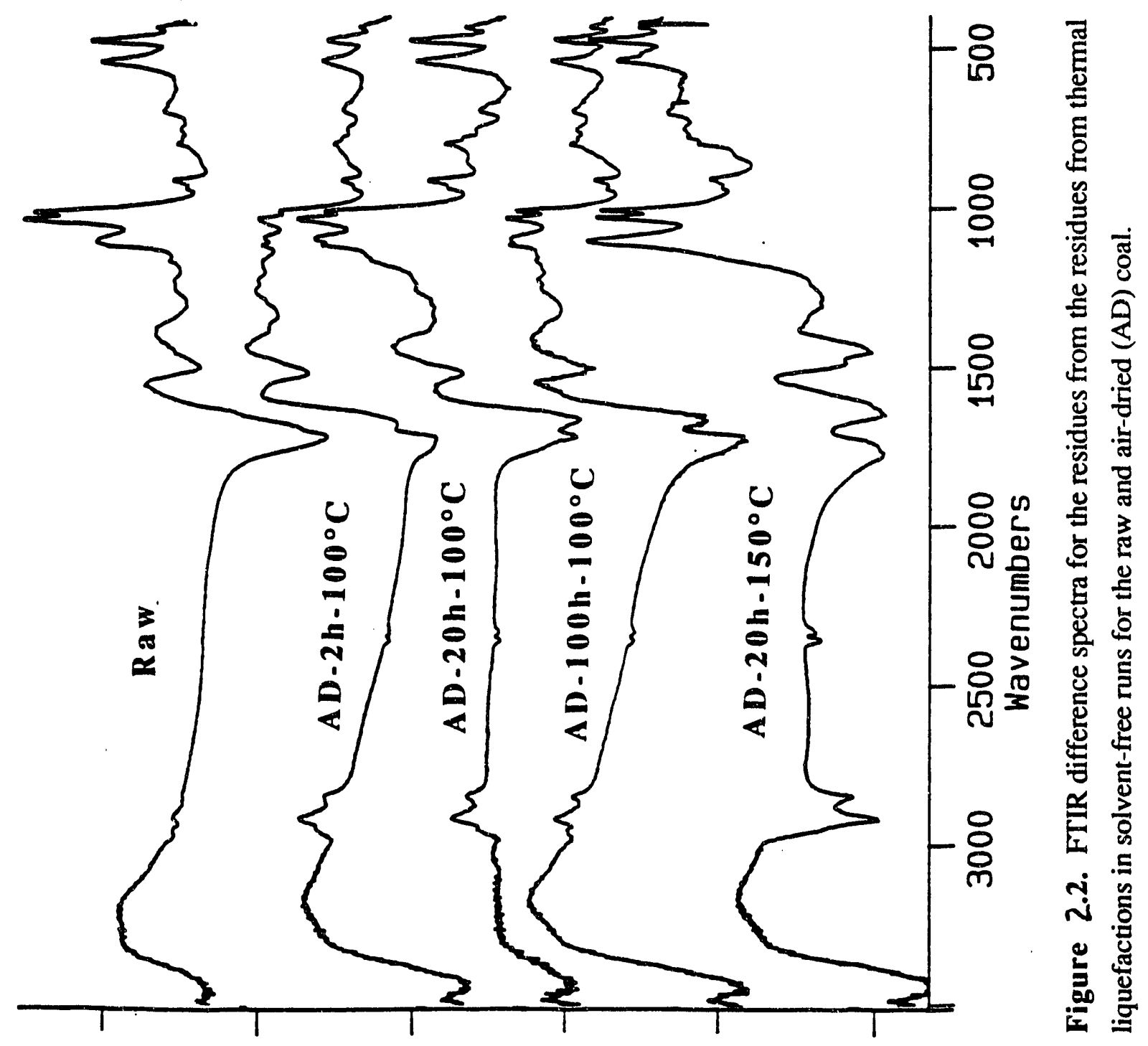

$<D \omega 0<D$ D 


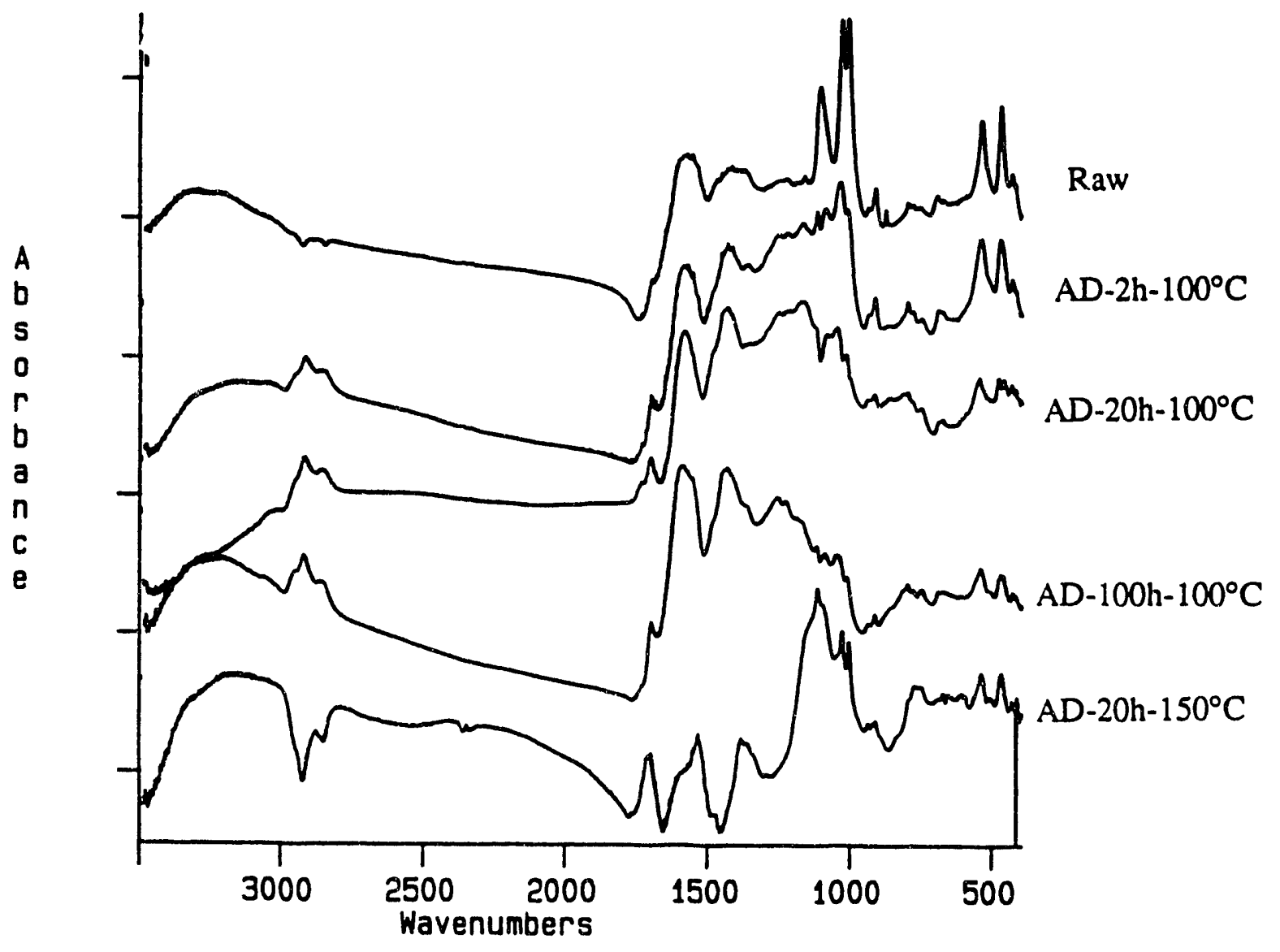

Figure 2.3. FTIR difference spectra for the residues from the residues from thermal liquefactions in the presence of tetralin for the raw and air-dried $(\mathrm{AD})$ coal. 


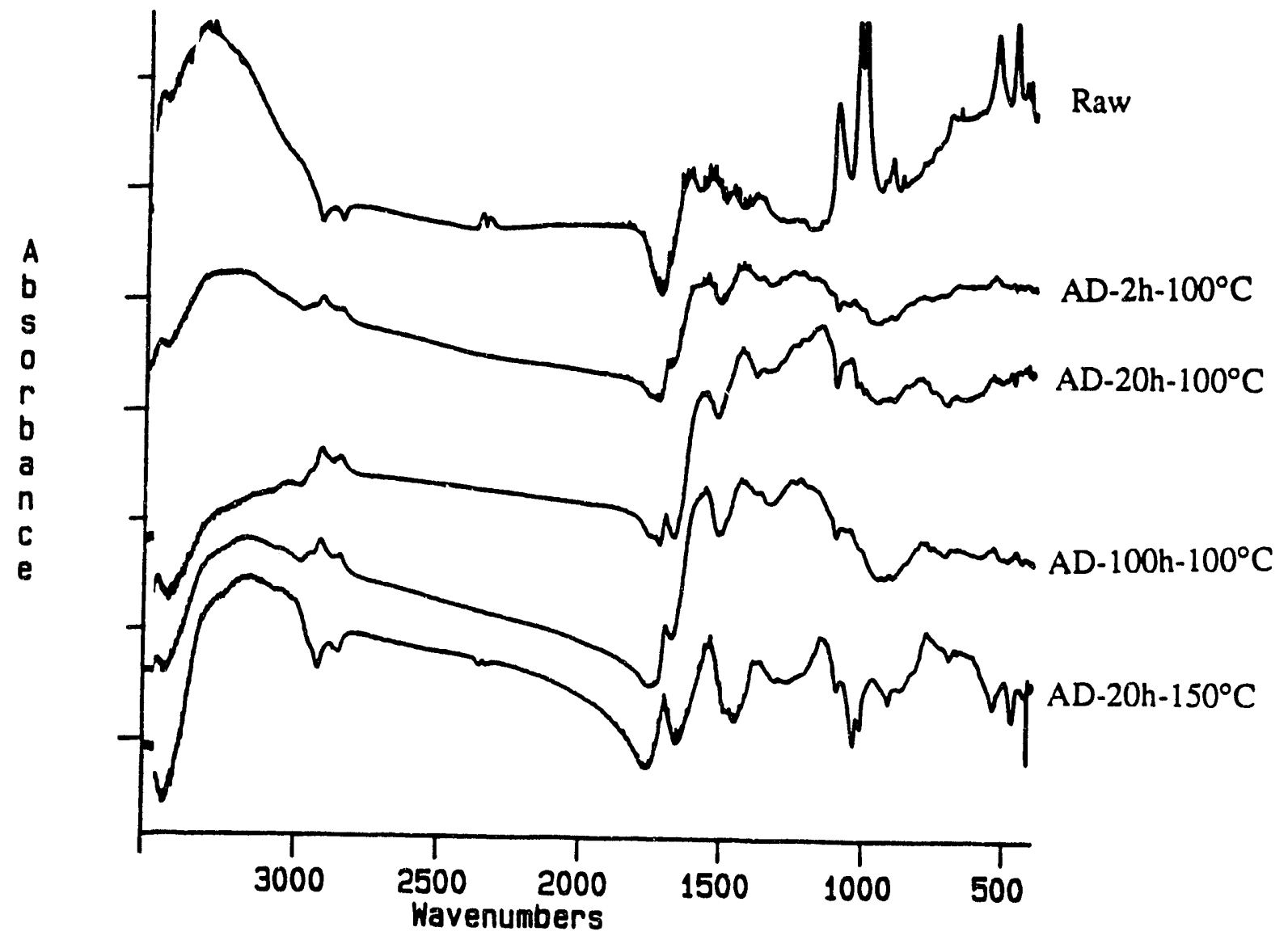

Figure 2.4. FTIR difference spectra for the residues from the residuts from thermal liquefactions in the presence of 1-methylnaphthalene for the raw and air-dried (AD) coal. 


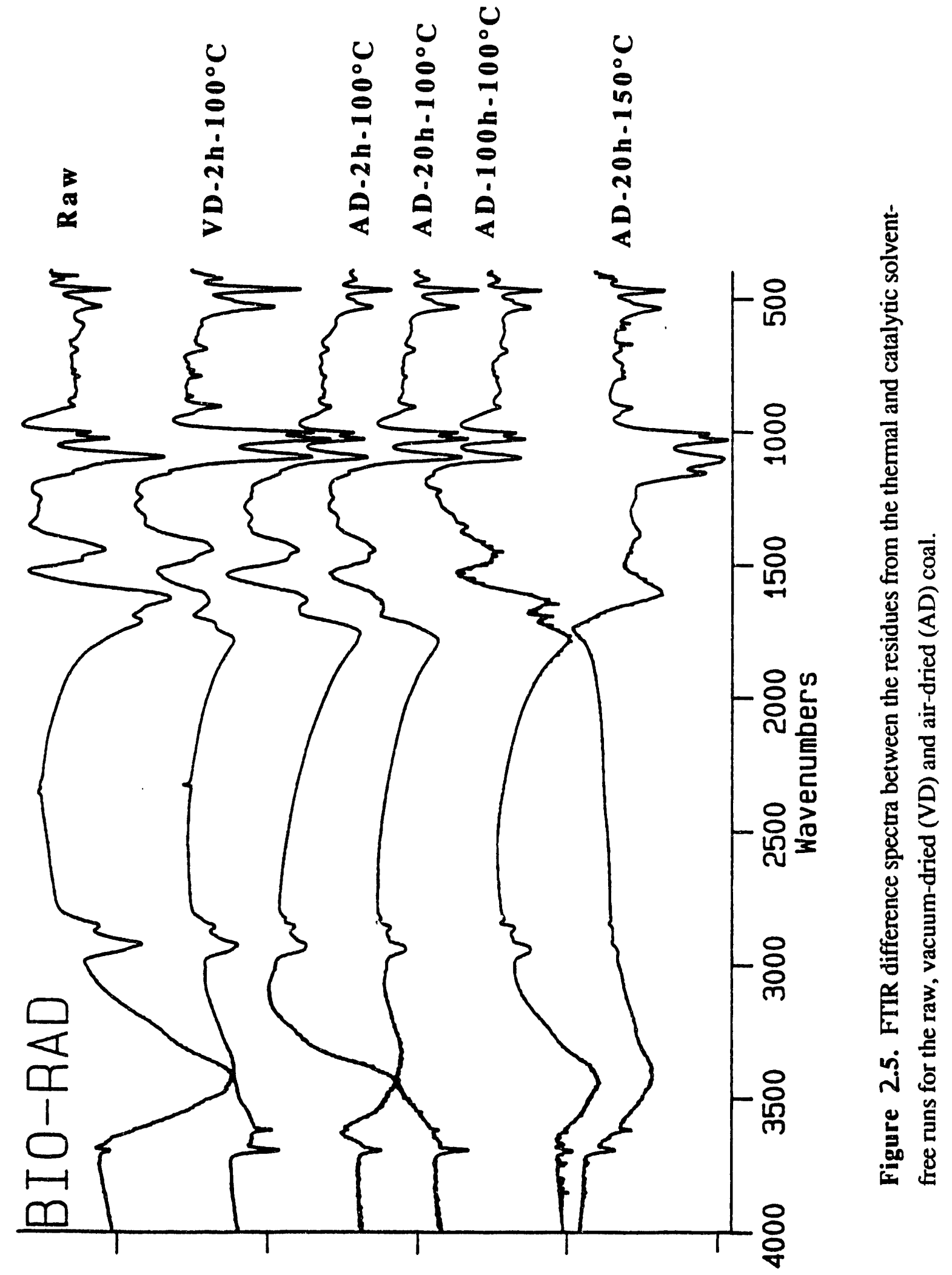

$\leftarrow$ ๔ ⿻ 


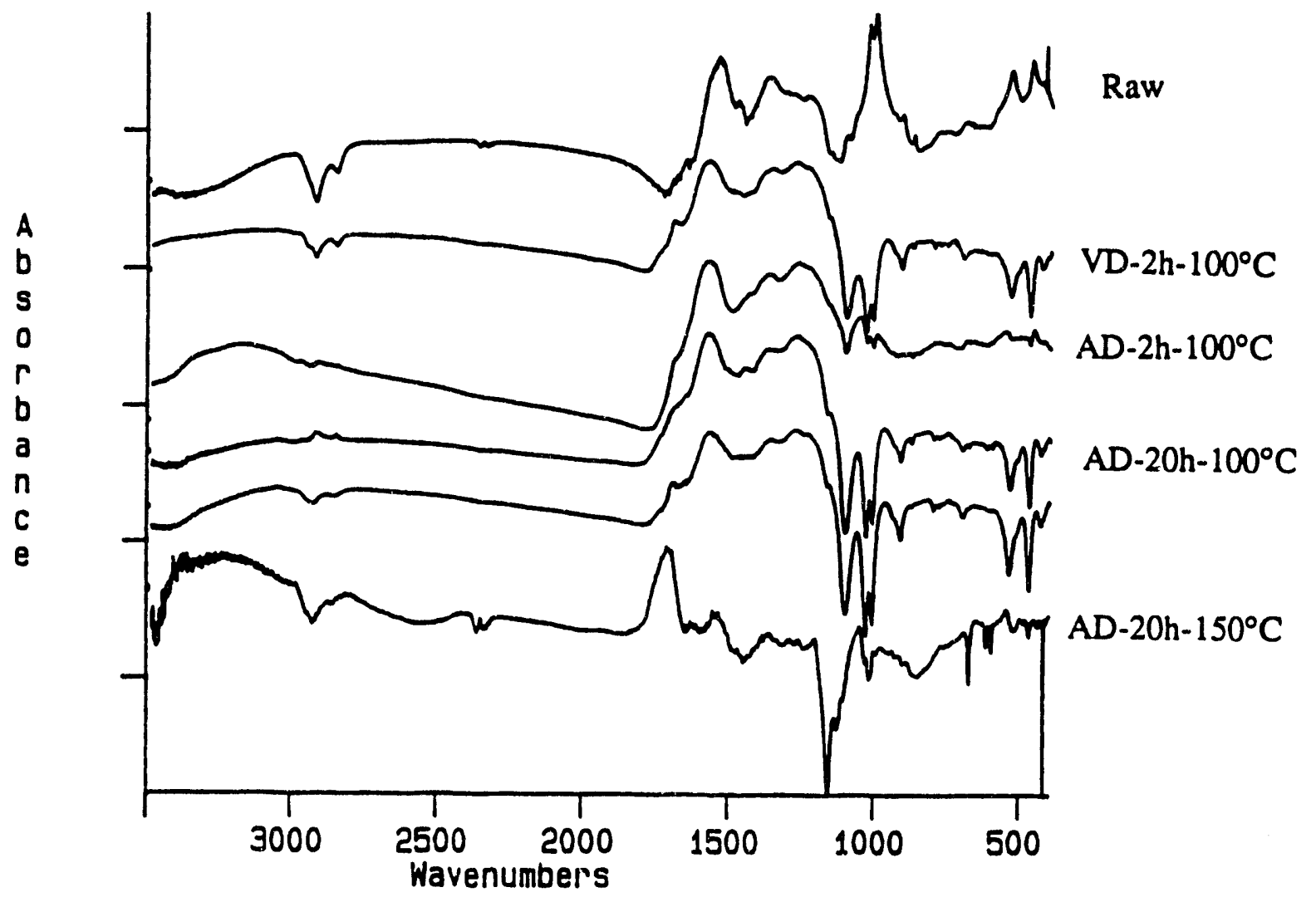

Figure 2.6. FTIR difference spectra between the residues from the thermal and catalytic runs in the presence of tetralin for the raw, vacuum-dried (VD) and air-dried (AD) coal. 


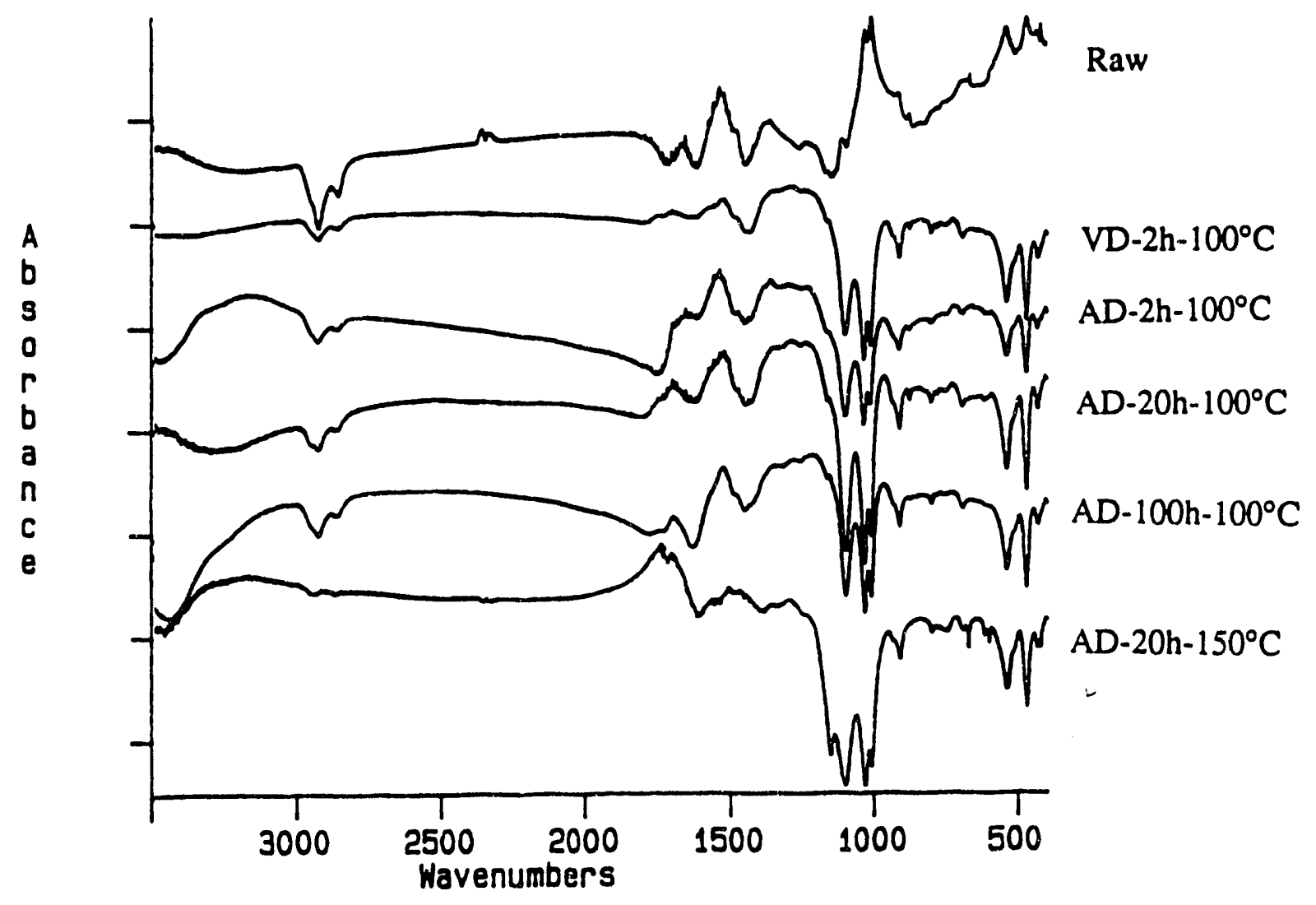

Figure 2.7. FTIR difference spectra between the residues from the thermal and catalytic runs in the presence of 1-methylnaphthalene for the raw, vacuum-dried (VD) and air-dried (AD) coal. 

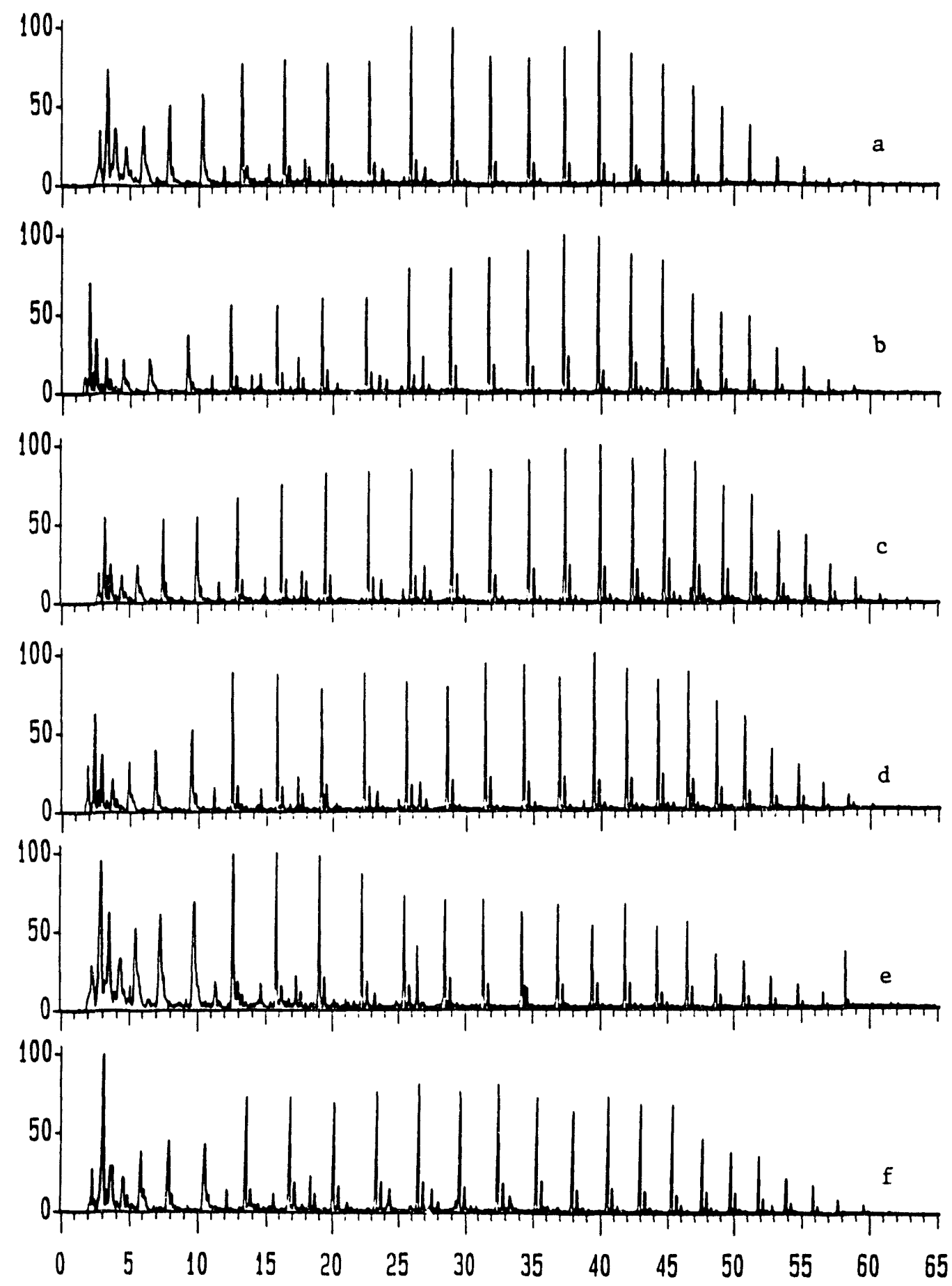

Figure 2.8. Selective ion monitoring of paraffins at $\mathrm{m} / \mathrm{z}$ from Py-GC-MS profiles of residues from thermal liquefactions of the coal a) raw, b) vacuum-dried at $100^{\circ} \mathrm{C}$, dried in air at $100^{\circ} \mathrm{C}$ for $\mathrm{c}$ ) $2 \mathrm{~h}, \mathrm{~d}) 20 \mathrm{~h}, \mathrm{e}) 100 \mathrm{~h}$, and f) dried at $150^{\circ} \mathrm{C}$ for $20 \mathrm{~h}$. 

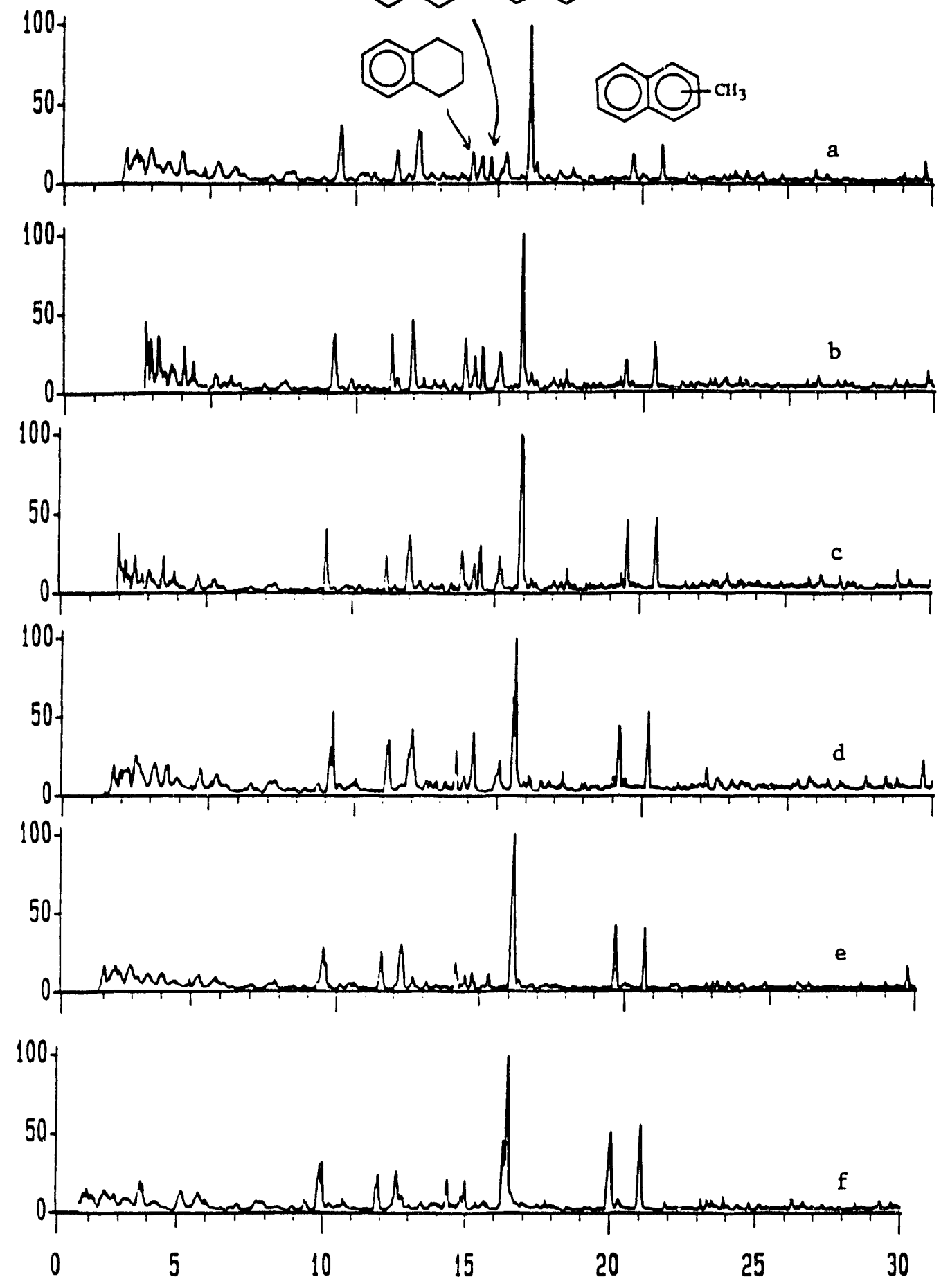

Figure 29. Py-GC-MS profiles of the residues from the thermal liquefactions in the presence of tetralin of the coal a) raw, b) vacuum-dried at $100^{\circ} \mathrm{C}$, dried in air at $100^{\circ} \mathrm{C}$ for c) $\left.2 \mathrm{~h}, \mathrm{~d}\right) 20 \mathrm{~h}, \mathrm{e}$ ) $100 \mathrm{~h}$, and $\mathrm{f}$ ) dried at $150^{\circ} \mathrm{C}$ for $20 \mathrm{~h}$. 


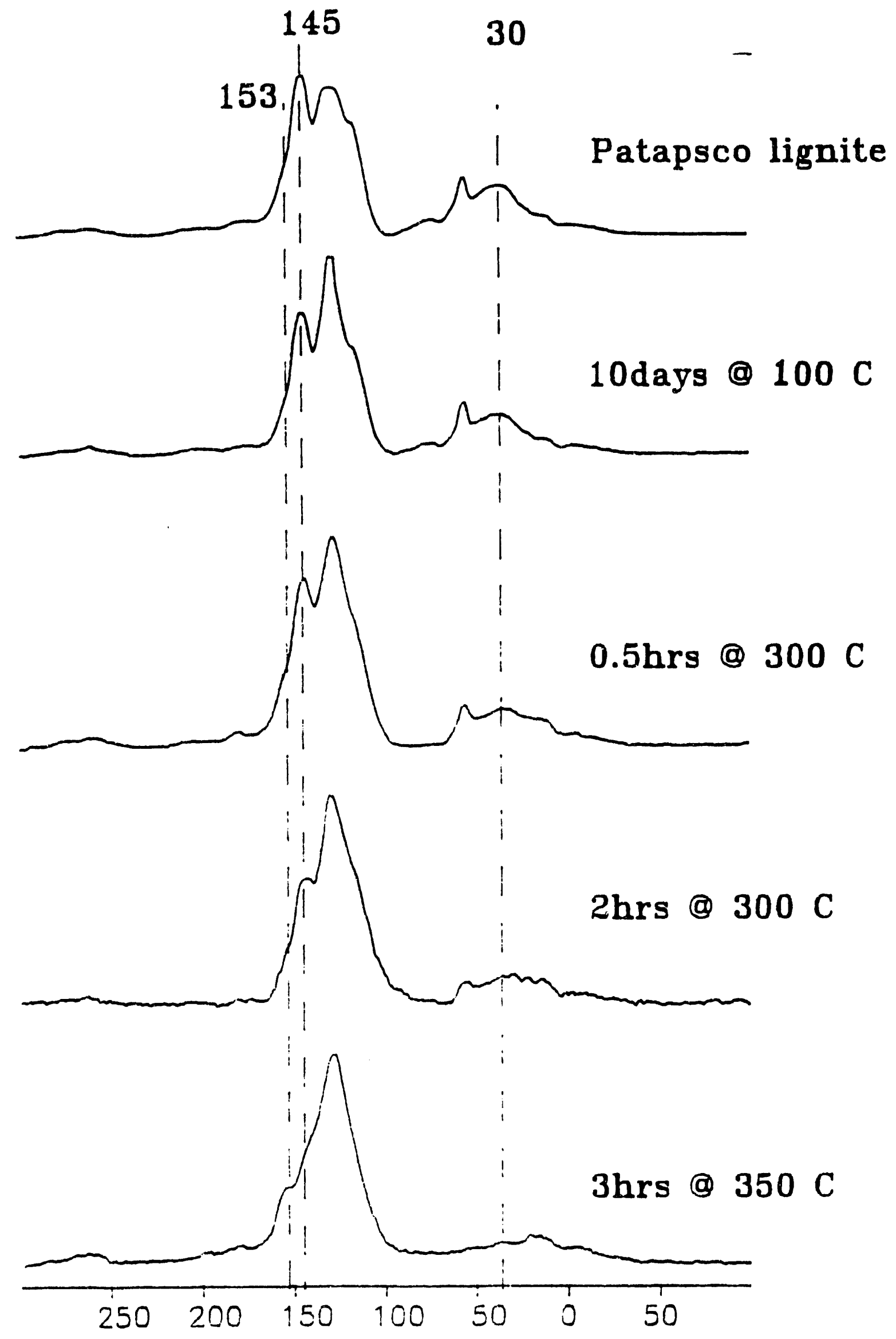

Figure 3.1 CPMAS ${ }^{13}$ NMR of the Patapsco lignite and the thermally altered residues. 


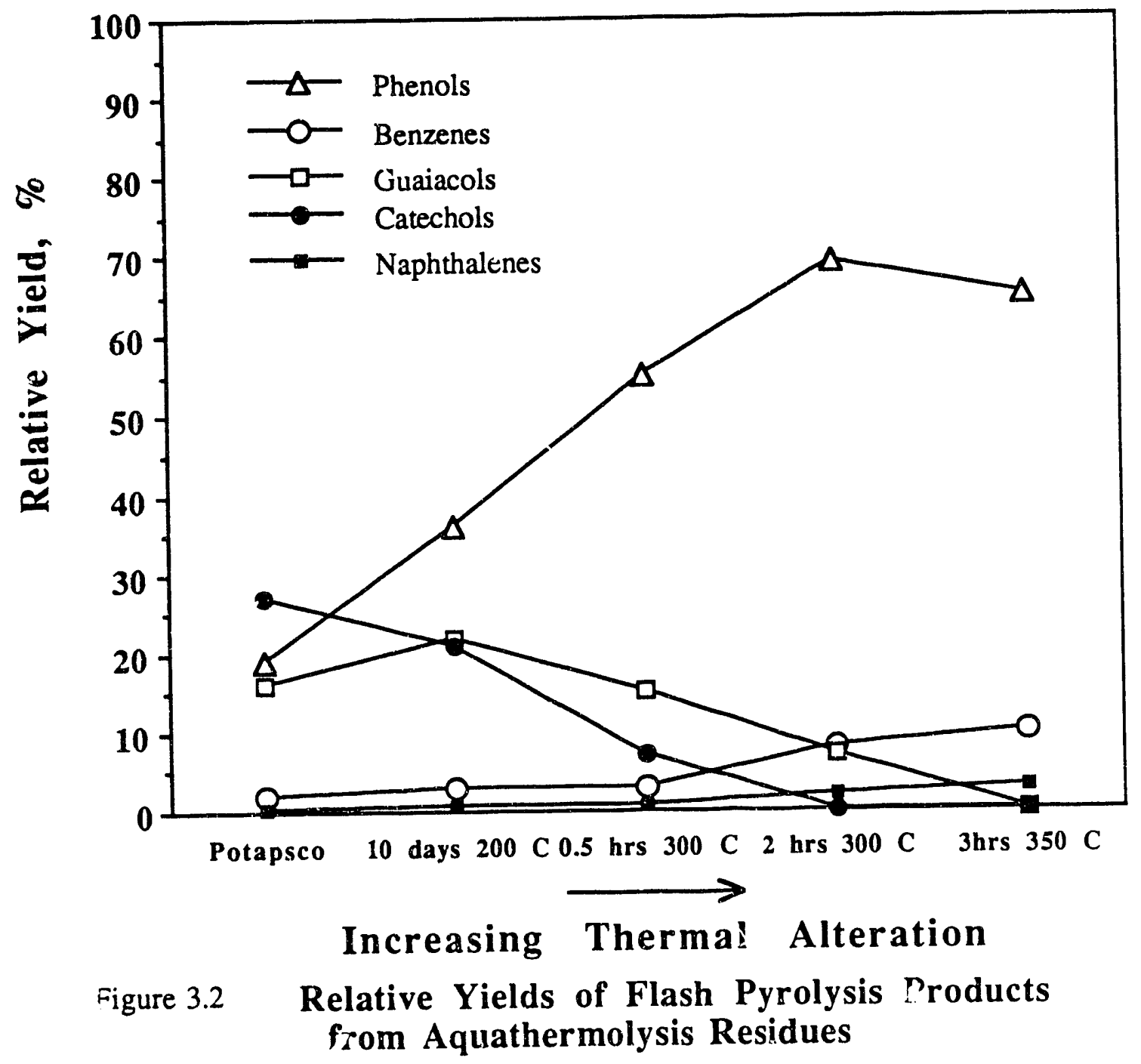



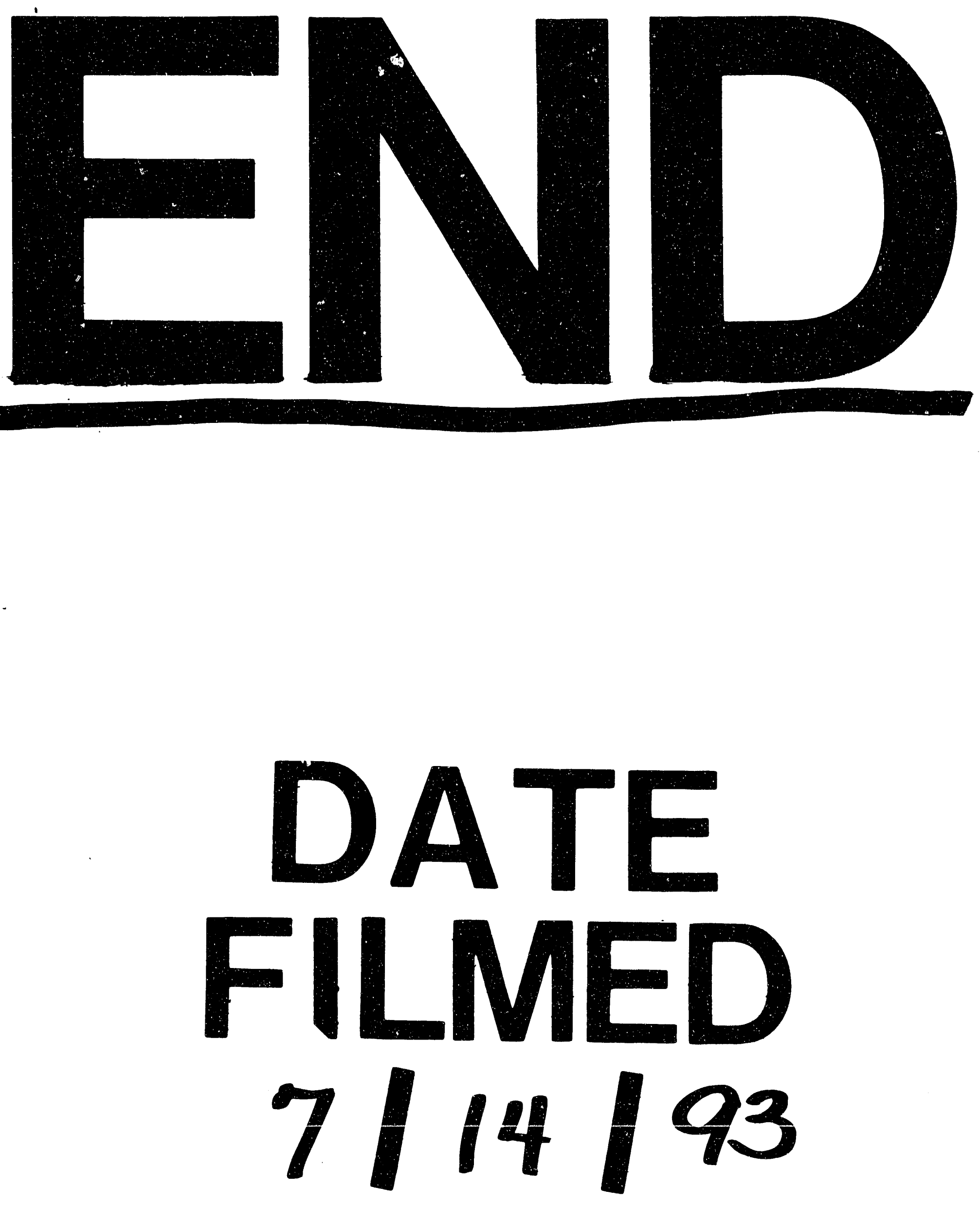
4 